ARTICLE

httpst//doi.org/10.1038/s41467-019-11111-1

\title{
Identification of intracellular cavin target proteins reveals cavin-PP1alpha interactions regulate apoptosis
}

Kerrie-Ann McMahon 1,7, Yeping Wu (1) 1,7, Yann Gambin 1,4, Emma Sierecki 1,4, Vikas A. Tillu (D) 1, Thomas Hall (1) 1, Nick Martel ${ }^{1}$, Satomi Okano ${ }^{1}$, Shayli Varasteh Moradi, ${ }^{1}$, Jayde E. Ruelcke ${ }^{2}$, Charles Ferguson ${ }^{1}$, Alpha S. Yap ${ }^{1}$, Kirill Alexandrov ${ }^{1,6}$, Michelle M. Hill (1) ${ }^{2}$ \& Robert G. Parton (1) ${ }^{1,3}$

Caveolae are specialized domains of the plasma membrane. Formation of these invaginations is dependent on the expression of Caveolin-1 or -3 and proteins of the cavin family. In response to stress, caveolae disassemble and cavins are released from caveolae, allowing cavins to potentially interact with intracellular targets. Here, we describe the intracellular (non-plasma membrane) cavin interactome using biotin affinity proteomics and mass spectrometry. We validate 47 potential cavin-interactor proteins using a cell-free expression system and protein-protein binding assays. These data, together with pathway analyses, reveal unknown roles for cavin proteins in metabolism and stress signaling. We validated the interaction between one candidate interactor protein, protein phosphatase 1 alpha (PP1 $\alpha$ ), and Cavin- 1 and -3 and show that UV treatment causes release of Cavin3 from caveolae allowing interaction with, and inhibition of, PP1 $\alpha$. This interaction increases H2AX phosphorylation to stimulate apoptosis, identifying a pro-apoptotic signaling pathway from surface caveolae to the nucleus.

\footnotetext{
${ }^{1}$ The University of Queensland, Institute for Molecular Bioscience, Brisbane, QLD 4072, Australia. ${ }^{2}$ The University of Queensland Diamantina Institute, Faculty of Medicine, The University of Queensland, Translational Research Institute, Brisbane, QLD 4102, Australia. ${ }^{3}$ The University of Queensland, Centre for Microscopy and Microanalysis, Brisbane, QLD 4072, Australia. ${ }^{4}$ Present address: EMBL Australia Node in Single Molecule Science, Lowy Cancer Building, Level 3 Medical Sciences UNSW Kensington Campus, Sydney, NSW 2052, Australia. ${ }^{5}$ Present address: Science and Engineering Faculty, Earth, Environmental and Biological Sciences, Genetics \& Biotechnology, Queensland University of Technology, Brisbane, QLD 4000, Australia. ${ }^{6}$ Present address: Institute for Future Environments, IFE Centres, CTCB Centre Office, Queensland University of Technology, Brisbane, QLD 4000, Australia. ${ }^{7}$ These authors contributed equally: Kerrie-Ann McMahon, Yeping Wu. Correspondence and requests for materials should be addressed to R.G.P. (email: r.parton@imb.uq.edu.au)
} 
C aveolae are a major membrane domain common to most vertebrate cells. Morphologically, caveolae appear as $50-100 \mathrm{~nm}$ vesicular structures near or attached to the plasma membrane ${ }^{1}$. One of the defining features of this domain is the integral membrane protein Caveolin-1 (CAV1). CAV1 is a defining structural component of caveolae that regulates diverse cellular processes, including endocytosis, vesicular transport, and mechanoprotection ${ }^{1}$. Recently, a family of cytosolic coat proteins, Cavin1/PTRF (caveolae-associated protein 1/Pol 1 transcription release factor), Cavin2/SDPR (caveolae-associated protein 2/ serum-deprivation response protein), Cavin3/PRKCDBP (caveolae-associated protein $3 /$ serum-deprivation response protein that binds to C-kinases), and Cavin4/MURC (caveolae-associated protein 4/Muscle-restricted coil-coil protein), were identified ${ }^{2-7}$.

The role of caveolae in mechanoprotection was first observed when the structural integrity of caveolae was disrupted by increased mechanical tension ${ }^{8,9}$. Under these conditions, caveolae flatten at the plasma membrane releasing cavin coat proteins into the cytosol. We proposed that these non-caveolar cavins may propagate signals to diverse intracellular effectors and have sought to establish the protein interaction network for noncaveolar cavins.

At present, no systematic analysis of the intracellular cavin interactome has been published. Cavin1 was initially demonstrated to be involved in transcriptional regulation by interacting with RNA polymerase 1 and dissociating the paused transcription complex involving transcription termination factor 1 (TTF-1) ${ }^{10}$. Cavin2 was originally described as a phosphatidylserine binding protein in platelets ${ }^{11}$. Subsequently, rat Cavin2 was isolated as a PKC-alpha binding protein and was observed to colocalize with CAV1 at caveolae ${ }^{12}$. Known Cavin3 interacting proteins include Myosin $1 c^{13}, c-M y c^{14}$, and the period circadian protein homolog 2 (PER2) and cryptochrome circadian regulator 2 (CRY2) complex involved in circadian rhythm ${ }^{15}$.

In order to define the intracellular cavin interactome, we utilized BioID/mass spectrometry (MS) of Cavin3. We speculated that release of cavins from caveolae would allow their interaction with intracellular targets. We therefore utilized MCF-7 cells, that lack caveolins, cavins and caveolae, as a model system to screen for putative interactors. Expressed cavin proteins in MCF-7 cells exhibit a cytosolic localization that mimics release of cavins from caveolae in cells subjected to increases in plasma membrane tension $^{8,9}$. Using this model system, we have generated a comprehensive list of potential interacting proteins for non-caveolar Cavin3. We have complemented this approach by screening in vitro expressed potential interacting proteins using Amplified Luminescent Proximity Homogeneous Assay Screen (ALPHAScreen; refs. ${ }^{16-18}$ ) as well as GFP-Trap pulldowns of Cavin3 in both MCF-7 and A431 cells.

We now demonstrate that in cells with caveolae and with endogenous cavin proteins, cavin proteins are released from caveolae in response to cellular stressors to allow their association with endogenous PP1a validating our approach. Our results suggest that released Cavin3 from caveolae plays an important proapoptotic role in response to UV treatment through interaction with, and inhibition of, PP1 $\alpha$ and provides the first identification of the cavin proteins as putative cytosolic signaling molecules.

\section{Results}

BioID analysis of non-caveolar cavin-interacting proteins. In order to define the non-caveolar cavin interactome, we utilized the BioID proximity-based biotinylation approach that allows for the characterization of protein-protein interactions in living cells $^{19}$. This method has the advantage of detecting weak and/or transient interactors without requiring that protein-protein interactions be maintained post lysis. As a system to identify potential non-caveolar cavin-interacting proteins, we sought a readily transfected cell line lacking caveolins and cavins in which we could identify non-caveolar and intracellular cavin-interacting proteins. For this, we tested a number of commonly used cell lines and found that MCF-7 cells (ATCC HTB-22) lack CAV1, Cavin1, Cavin2, Cavin3 at the mRNA level (Supplementary Fig. 1e) and Cavin1 and CAV1 at the protein level (Supplementary Fig. 1b-d). In the absence of CAV1 (and caveolae), expressed cavin proteins show a cytosolic distribution (Supplementary Fig. 1f-i). This allows us to mimic the interaction between cavins after release from caveolae and downstream proteins. CAV1-GFP had a Golgi/ vesicular distribution in MCF-7 cells (Supplementary Fig. 1j). Furthermore, expression of Cavin1, Cavin2, Cavin3, or CAV1 alone in MCF-7 cells did not induce endogenous expression of the other cavin or CAV1 genes (Supplementary Fig. 1a-d). Cavin3 can be released from caveolae in response to increased tension on the membrane as a Cavin1-Cavin3 subcomplex or as monomeric Cavin 3 which is a unique feature among all cavin proteins ${ }^{8}$. We therefore generated a Cavin 3 construct tagged with BirA in an IRES-GFP vector to better control expression and expressed Cavin3-BirA alone in MCF-7 cells followed by streptavidin affinity purification and peptides identified by MS. Cell extracts expressing BirA alone were subjected to the same analysis as the control. Nonspecific polypeptides from cells expressing BirA alone were removed from our proteomics lists and only proteins with two or more peptides were subsequently included.

For non-caveolar Cavin3, 29 specific proteins were identified including fructose-bisphosphate aldolase (FBA) A and pyruvate kinase $\mathrm{M}$ (PKM), as well as the serine/threonine-protein phosphatase PP1alpha (PP1 $\alpha$ ) (yellow boxes, Supplementary Data 1). Ingenuity pathway analysis revealed several enzymes in glycolysis/gluconeogenesis for non-caveolar Cavin3 and molecular and cellular functions related to cell death and survival (Supplementary Fig. 2a).

In addition to the BioID/MS and as an independent validation, Cavin3-GFP was expressed in MCF-7 (cytosolic localization, gray boxes) and A431 cells (caveola localization, blue boxes) and GFP Trap pulldown experiments were performed followed by MS (Supplementary Data 1). Cell extracts expressing GFP alone were subjected to the same analysis and polypeptides that interact nonspecifically with the GFP beads were removed from our proteomics lists. Fifty-six specific proteins were observed in the Cavin3-GFP/MCF-7 GFP pulldowns (gray boxes, Supplementary Data 1) and 44 specific proteins were observed in the Cavin3-GFP/A431 GFP pulldowns (blue boxes, Supplementary Data 1). Five proteins interacted with Cavin3 in both MCF-7 and A431 GFP pulldowns, including histone deacetylase 2 (HDAC2), TAR DNA binding protein (TARDBP) 43, gammaglutamylcyclotransferase (GGCT), annexin A5 (ANXA5), and PP1a (purple boxes, Supplementary Data 1).

ALPHAScreen/in vitro expression analysis. To begin characterizing these potential non-caveolar cavin-interacting proteins, 47 proteins were chosen for further analysis using ALPHAScreen, a sensitive bead-based proximity assay $8,16-18,20$. The protein list was a broad selection of proteins with diverse functions derived from the BioID, such as peroxiredoxin-6 (PRDX6) and the PP1a, and from literature searches as either potential cavin-interacting proteins (Supplementary Table 1) or proteins with links to caveolar functions. For example, dual specificity tyrosine-(Y)phosphorylation regulated kinase 3 (DYRK3) and serine/threonine-protein kinase A-Raf (ARAF) were identified as proteins important in caveolar-mediated endocytosis ${ }^{21}$. The circadian 


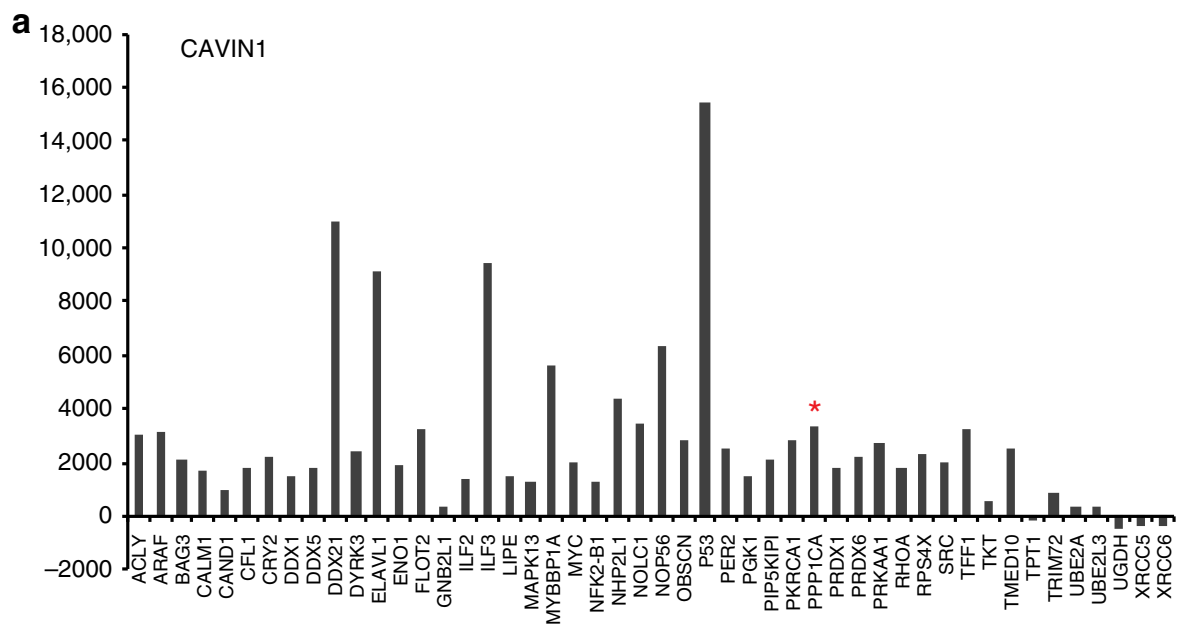

d

b

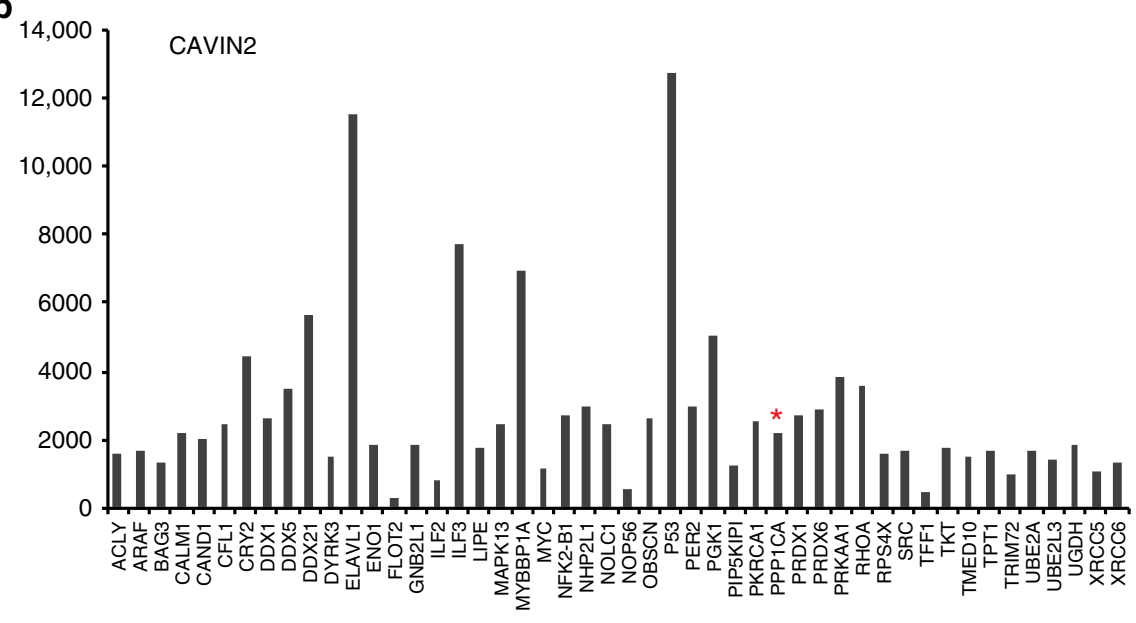

c

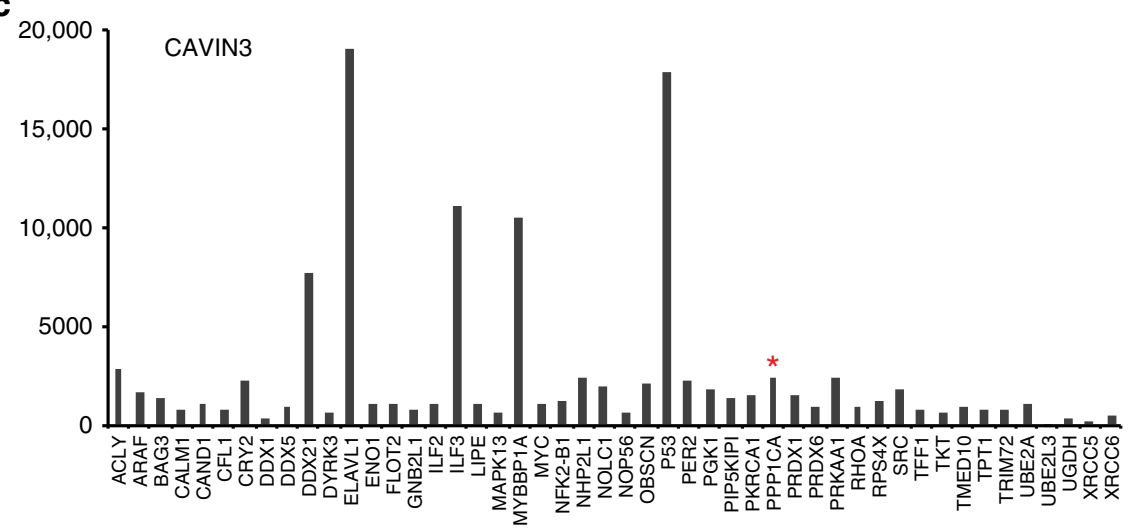

ACLY

ARAF

BAG3

CALM1

CAND1

CFL1

CRY2

DDX1

DDX5

DDX21

DYRK3

ELAVL1

ENO1

FLOT2

GNB2L1

ILF2

ILF3

LIPE

MAPK13

MYBBP1A

MYC

NFK2-B1

NHP2L1

NOLC1

NOP56

OBSCN

P53

PER2

PGK1

PIP5KIPI

PKRCA1

PPP1CA

PRDX1

PRDX6

PRKAA1

RHOA

RPS4X

SRC

TKT

TMED10

TPT1

TRIM72

UBE2A

UBE2L3

UGDH

XRCC5

XRCC6
CAVIN1 CAVIN2 CAVIN3

\begin{tabular}{l|l|l|}
3002.5 & 1617 & 2816.5
\end{tabular}

$3117.7 \quad 1699.7 \quad 1577.4$

\begin{tabular}{r|r|r}
2153.6 & 1328.8 & 1317.6 \\
\hline
\end{tabular}

\begin{tabular}{|l|r|r}
1680.3 & 2229.3 & 777 \\
\hline
\end{tabular}

$1004 \quad 2038.8 \quad 986.75$

$1823.8 \quad 2408.8 \quad 745.5$

\begin{tabular}{|l|l|l|}
2255 & 4433.8 & 2198.3 \\
\hline
\end{tabular}

\begin{tabular}{|l|r|r|}
\hline 1536.8 & 2582.8 & 277.8 \\
\hline
\end{tabular}

\begin{tabular}{|l|l|l|}
1819.5 & 3518.5 & 941.3 \\
\hline
\end{tabular}

$\begin{array}{lll}10978.5 & 5651.8 & 7652.8\end{array}$

\begin{tabular}{|l|r|r|}
\hline 2462.1 & 1489.5 & 635.3 \\
\hline
\end{tabular}

$\begin{array}{rrrr}9125.1 & 11574.3 & 18899.4\end{array}$

\begin{tabular}{|l|l|l|}
1929.75 & 1823.5 & 1027
\end{tabular}

\begin{tabular}{|l|r|r|}
3294.6 & 251.6 & 992.6 \\
\hline
\end{tabular}

\begin{tabular}{|r|r|r|}
\hline 372 & 1867.5 & 738 \\
\hline
\end{tabular}

\begin{tabular}{l|l|l|}
1405.2 & 831.7 & 979.3
\end{tabular}

$\begin{array}{lll}9438.1 & 7713.6 & 11033\end{array}$

\begin{tabular}{r|r|r}
1484.8 & 1801.6 & 1025.9
\end{tabular}

\begin{tabular}{l|l|l|}
1247.5 & 2446.8 & 655 \\
\hline
\end{tabular}

$\begin{array}{llr}5593.1 & 6955.3 & 10368.7\end{array}$

\begin{tabular}{l|l|l}
2034.5 & 1131.3 & 1079.2
\end{tabular}

\begin{tabular}{|l|l|r|}
\hline 1236.4 & 2678.3 & 1110.5 \\
\hline
\end{tabular}

\begin{tabular}{|l|l|l|l|}
\hline 4393 & 3006.2 & 2349.1 \\
\hline
\end{tabular}

\begin{tabular}{|l|l|r|}
\hline 3462.4 & 2493.6 & 1979.9 \\
\hline
\end{tabular}

\begin{tabular}{|r|r|r|}
\hline 6330.9 & 590.4 & 521.9 \\
\hline 2865.3 & 2608.3 & 1988.5 \\
\hline
\end{tabular}

\begin{tabular}{rrr}
2865.3 & 2608.3 & 1988.5 \\
\hline 15376.8 & 12779.5 & 17864
\end{tabular}

\begin{tabular}{l|l|l|}
2558 & 2969.5 & 2263.5 \\
\hline
\end{tabular}

\begin{tabular}{|l|r|r}
1539.5 & 5034 & 1820.5 \\
\hline
\end{tabular}

\begin{tabular}{|l|r|r|}
\hline 2064.3 & 1213.4 & 1381.57 \\
\hline
\end{tabular}

\begin{tabular}{|l|r|r|}
2818.8 & 2504 & 1537.5 \\
\hline
\end{tabular}

\begin{tabular}{l|l|l}
3391.8 & 2193.3 & 2321.3 \\
\hline
\end{tabular}

\begin{tabular}{|l|l|l|}
1845 & 2716.5 & 1473 \\
\hline
\end{tabular}

\begin{tabular}{l}
$2220 \quad 2890$ \\
\hline
\end{tabular}

\begin{tabular}{l|l|l}
2715 & 3836.5 & 2420
\end{tabular}

$1828.8 \quad 3605.3 \quad 909$

\begin{tabular}{|l|r|r}
\hline 2271 & 1546.6 & 1160.3 \\
\hline
\end{tabular}

\begin{tabular}{|l|l|l|}
$2000.7 \quad 1698.5 \quad 1783.6$ \\
\hline
\end{tabular}

\begin{tabular}{l|l|l}
565 & 1729.3 & 542
\end{tabular}

\begin{tabular}{l|l|l}
2502.7 & 1521.3 & 813 \\
\hline
\end{tabular}

\begin{tabular}{r|r|r|r}
-187.5 & 1630 & 780 \\
\hline 921.1 & 987.1 & 746.8 \\
\hline
\end{tabular}

\begin{tabular}{|l|l|r|}
\hline 320.3 & 1710 & 1075.5 \\
\hline
\end{tabular}

$308 \quad 1415$

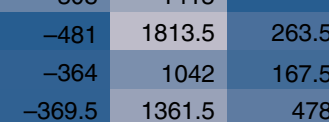

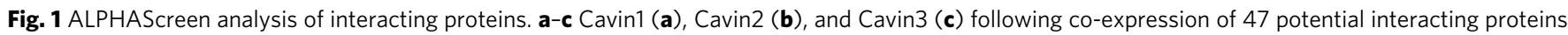
in the eukaryotic Leishmania tarentolae-based cell-free-expression system. Each protein pair was tested in triplicate and values above 2000 counts were considered positive interactions. Red = positive interactions, blue = no interactions. *PPP1CA serine/threonine-protein phosphatase PP1alpha catalytic subunit. d Interaction heatmap of the mean values of 47 tested potential interacting proteins with each of Cavin1, Cavin2, and Cavin3 from three independent experiments

rhythm proteins, PER2, and CRY2 were previously identified in a complex with Cavin 1 and Cavin $3^{15}$, and Cavin1 was independently identified as a potential CRY2 interacting protein ${ }^{22}$. ATP citrate lyase (ACLY) exhibited decreased expression in adipose tissue of Cavin3 knockout mice and was also included in the ALPHAScreen $^{23}$. We next systematically analyzed pairwise direct interactions between each of the cavin proteins, Cavin1 (Fig. 1a),
Cavin2 (Fig. 1b), and Cavin3 (Fig. 1c), following co-expression of 47 possible interacting partners in our cell-free system. Cavin2 was included here for comparison. The recently developed eukaryotic Leishmania tarentolae-based cell-free-expression system (LTE) was used to accelerate conversion of DNA to protein $^{24,25}$ and allows examination of direct protein-protein interactions with expression of full-length, functional proteins 
with precise stoichiometry control of the co-expressed proteins in a $3 \mathrm{~h}$ period ${ }^{16-18,24,25}$. We recently demonstrated that cavin proteins produced in this system have the same behavior as in mammalian cells ${ }^{8}$. In the interaction screen, each protein pair was reconstituted by co-expression, and relative expression levels were determined by measuring the fluorescence of GFP and mCherry tags. From previous experiments ${ }^{16,17}$, a threshold of above 2000 (background) selected positive interactions and was employed in these studies. For Cavin3, this threshold corresponds to the top 20-25\% binding intensities. The luminescence intensities are plotted as averages over three independent expressions/experiments where for each experiment, the signal intensity from a negative control, GFP alone in solution, was subtracted. An average of all the normalized data for both configuration of each protein pair (GFP-protein A/protein B-Cherry or GFP-protein B/ protein A-Cherry) was calculated to provide the binding index that is presented using a heatmap plot (Fig. 1d). Positive interactions are indicated as red bars. In addition, ALPHAScreen intensity response as a function of protein dilution was measured for different proteins binding to Cavin3 (Supplementary Fig. 3a) as well as for each of the cavin proteins and PP1a (Supplementary Fig. 3b).

A proportionate Venn diagram was generated to determine the interacting proteins that are common and specific for each of Cavin1, Cavin2, and Cavin3 from the ALPHAScreen (Supplementary Fig. 4). This analysis revealed 13 proteins, including ELAV-like RNA-binding protein 1 (ELAV1), p53, and PP1a, that can interact independently with each cavin proteins. ACLY specifically interacted with Cavin1 and Cavin3, while nucleolar protein 56 (NOP56) interacted only with Cavin1. Taken together these complementary proteomic and interaction approaches provided a tentative list of potential non-caveolar intracellular cavin-interacting proteins and helped establish bona fide interactors for further analysis (Supplementary Data 1). These were derived from BioID/MS (yellow, Supplementary Data 1), ALPHAScreen (green, Supplementary Data 1), literature searches (orange, Supplementary Data 1), Cavin3-GFP/MCF-7/MS (gray, Supplementary Data 1) and Cavin3-GFP/A431/MS (light blue, Supplementary Data 1), and proteins identified in both GFP Trap MCF-7 and A431 cells (purple boxes, Supplementary Data 1). The approaches used (ALPHAScreen, BioID and GFP Trap/MS) have differing advantages/disadvantages for protein identification (see Discussion section). Given that PP1 $\alpha$ was the only protein identified in multiple approaches (BioID and GFP Trap/MS experiments from A431 and MCF-7 cells expressing Cavin3GFP), and importantly, showed a direct interaction with in vitro synthesized cavins by ALPHAScreen, we focused our attention on the role of this interaction in our model cell systems.

PP1a associates with cavin proteins. In order to validate the interaction between PP1 $\alpha$ and the cavin proteins, we first exogenously expressed mCherry-tagged Cavin1, Cavin2, and Cavin3, respectively, with GFP-PP1a in MCF-7 cells. Western blot analysis of the cytosolic fractions after GFP Trap pulldown revealed coprecipitation of mCherry-Cavin 1 and mCherry-Cavin3 with GFP-PP1a (Fig. 2a) consistent with the interaction profile from the ALPHAScreen analysis. Conversely, western blot analysis of GFP Trap pulldown from MCF-7 cell cytosolic fractions with exogenously expressed GFP-tagged Cavin1, Cavin2, and Cavin3 coprecipitated with endogenous PP1a (Fig. 2b). Cavin2-GFP exhibited lower interaction levels with endogenous PP1a compared with Cavin1-GFP and Cavin3-GFP (Fig. 1b), which is consistent with the results shown in the cell-free system by ALPHAScreen (Fig. 1d). These results collectively suggest a weaker or less stable interaction between PP1 $\alpha$ and Cavin2, therefore, all subsequent experiments focused on the interaction of PP1a with Cavin1 or Cavin3.

As an independent test of association of cavin proteins with PP1 $\alpha$ in cells, proximity ligation assay (PLA) was performed to assess the association of endogenous PP1a with exogenously expressed GFP-tagged Cavin 1 and Cavin3. As shown in Fig. 2c, d, there was a significant association between each of the GFPtagged cavin proteins with PP1 $\alpha$ as compared with control GFP/ MCF-7 cells. Single-molecule coincidence (SMC) analysis ${ }^{8}$ was further employed to validate the interaction between PP1a and Cavin1 and Cavin3. Based on the larger amplitude of the bursts observed for Cavin1, we can deduce that Cavin1 primarily exists in an oligomeric state when expressed in MCF-7 cells. The amplitude of bursts observed for Cavin3 correspond to the brightness of individual mCherry fluorophores, confirming that Cavin3 primarily exists in a monomeric state (Fig. 2e, f). The coincidence ratio for GFP-PP1a and mCherry-Cavin1 at 0.7 suggested that PP1 $\alpha$ binds to oligomeric Cavin1. For Cavin3, the coincidence ratio at 0.5 , suggested a $1: 1$ interaction between PP1a and Cavin3 (Fig. 2f). These findings confirm that heterologous expressed Cavin 1 and Cavin3 can associate with PP1 $\alpha$ in these model systems.

We further characterized the interaction between Cavin3 or Cavin1, and PP1a. We designed truncation mutants guided by amino acid alignment to the two major domains in Cavin 1 and Cavin3, helical region 1 (HR1; amino acids aas 48-164 in Cavin1; aas 14-130 in Cavin3; Fig. 3a) and HR2 domain (aas 209-300 in Cavin1; aas 160-210 in Cavin3; Fig. 3a) ${ }^{26}$. AlphaLISA assay was used to test the interaction between in vitro synthesized PP1 $\alpha$ and truncation mutants of Cavin3 and Cavin1. The co-expression efficiency of PP1 1 -mCherry and GFP-tagged cavin constructs were examined in an LTE system (Supplementary Fig. 5). As was observed in MCF-7 cells, constructs containing the HR2 domain of Cavin 3 can associate with PP1a but not those containing only the HR1 domain (Fig. 3b). These results were further validated by GFP-Trap assay in MCF-7 cells transfected with GFP-tagged transgenes. Endogenous PP1 $\alpha$ interacted with full-length Cavin3, a mutant containing both the HR1 and HR2 domains, the HR2 domain alone, but not the HR1 domain alone (Fig. 3d, e). In addition, the AlphaLISA assay revealed that, similar to Cavin3, constructs containing the HR2 domain of Cavin1 showed significantly increased association with PP1a compared with the HR1 domain alone. Collectively, these findings suggest that PP1a interacts directly with the HR2 domains of Cavin1 and Cavin3.

PP1a associates with cavin proteins released from caveolae. We next sought to investigate the proposed interaction between PP1a and cavin proteins in a cellular system. We focused on A431 cells that have been used extensively for caveolae studies due to an abundance of caveolae $e^{27,28}$ and because, as an epidermoid skin cancer cell line, these cells have been used extensively in experiments investigating UVC irradiation, as explored later in this study ${ }^{29,30}$. During the course of these experiments, we determined that A431 cells (similar to several other commonly cancer cell lines such as HeLa cells) do not express Cavin2 but have significant expression of the universal components of caveolae, Cavin1, CAV1, and Cavin3. We also employed the human breast cancer cell line, MDA-MB-231 as an additional cell type.

Under control conditions PP1a was mainly localized in the nucleus of A431 cells while the Cavin1 and Cavin3 proteins exhibited a predominantly caveolar distribution at the plasma membrane (Fig. 4a, b, upper panels). This lack of colocalization suggests that the proteins can only interact if caveolae are disassembled. As a model system we subjected A431 cells to hypo-osmotic medium to induce caveola disassembly. Electron 

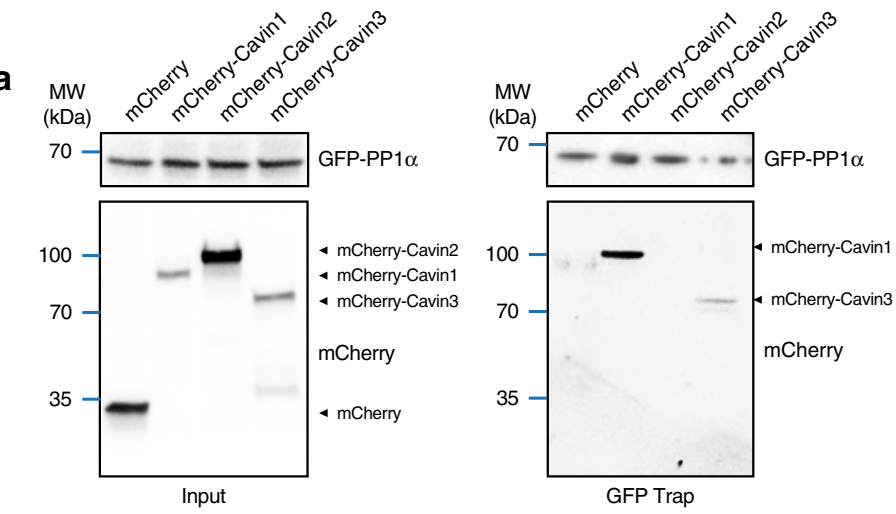

C
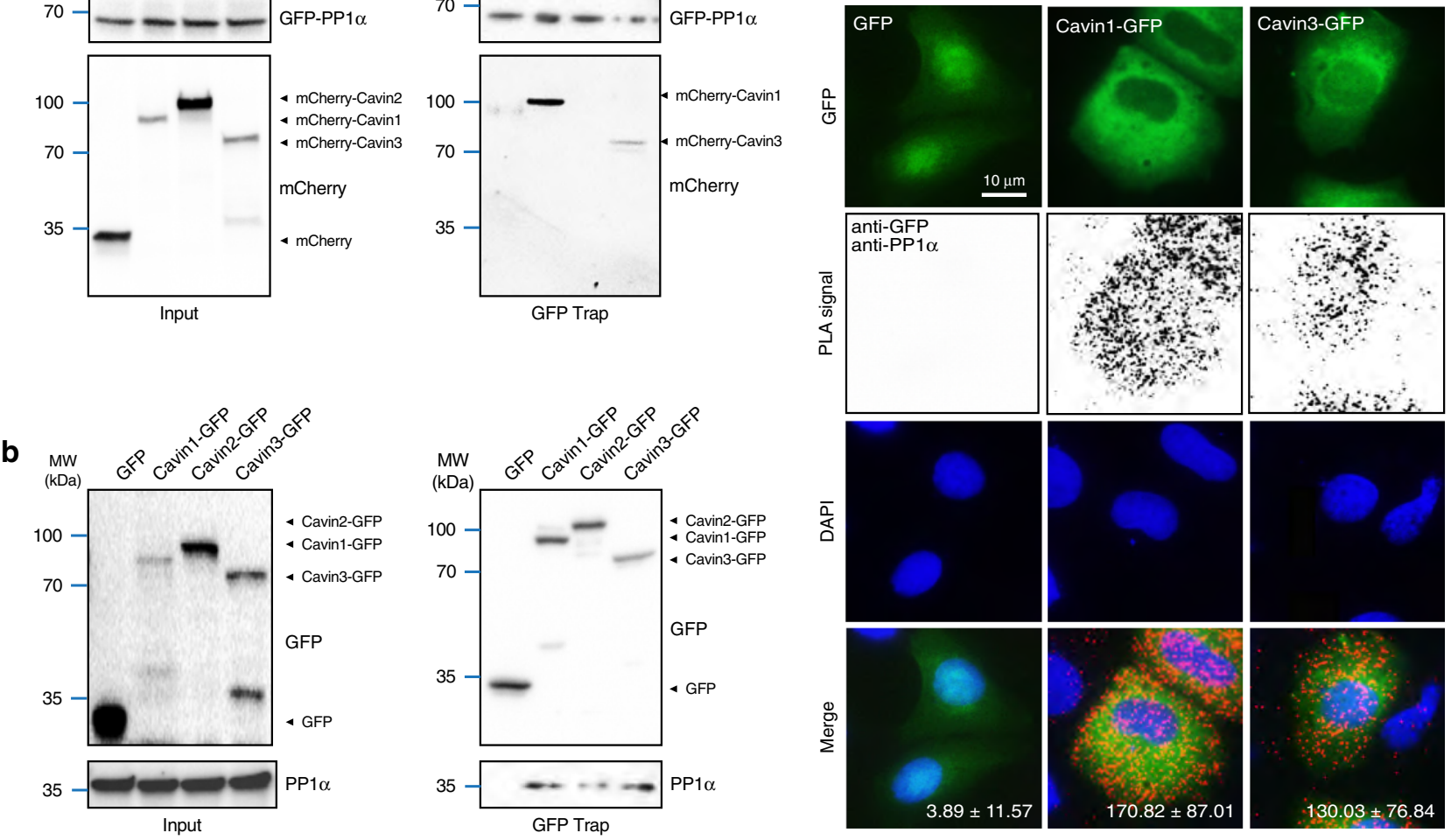

d

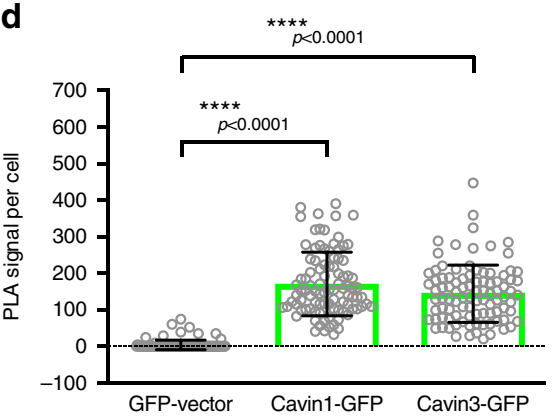

e

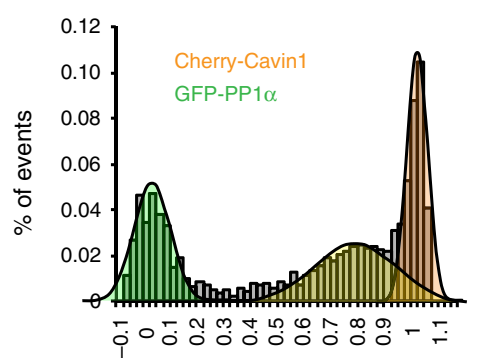

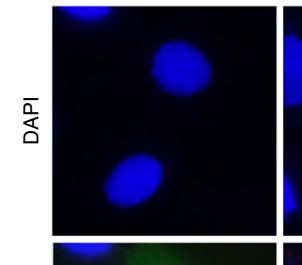
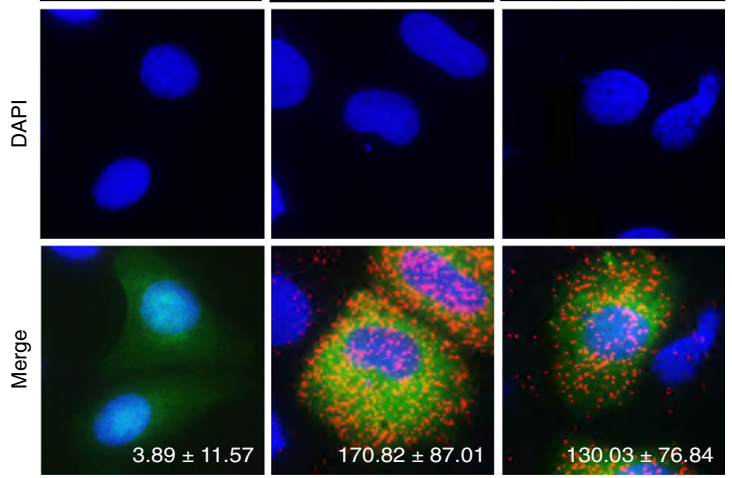

f

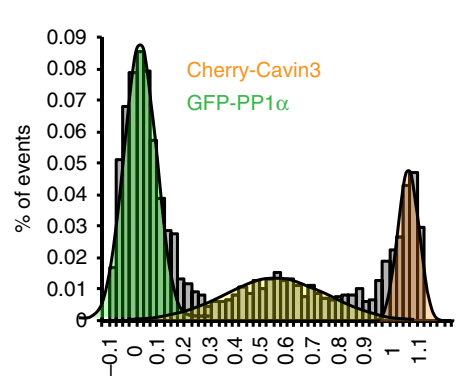

Fig. 2 Interaction between the cavin proteins and PP1 $\alpha$. a GFP Trap assays of MCF-7 cells cotransfected with GFP-PP1 $\alpha$ and mCherry-vector, mCherryCavin-1, -2 or -3. Transfection efficiency was examined in the input material (left panel). mCherry was detected in the GFP pulldown samples by western blot analysis (right panel). b Input and pulldown samples for GFP Trap assays of Cavin-GFP cells were analyzed by western blotting for GFP and PP1 $\alpha$, with GFP-vector as the negative control. $\mathbf{c}$ In situ PLA detection (red puncta) of the interaction between GFP-cavins and endogenous PP1 $\alpha$ in MCF-7 cells using anti-GFP (mouse) and anti-PP1 $\alpha$ (rabbit) antibodies. DNA was stained by DAPI (blue). Red puncta per cell is represented as mean \pm SEM for three experiments from different fields of view. Scale bar, $10 \mu \mathrm{m}$. d Quantification of PLA puncta/cell for 150 total cells ( $n=50$ cells per experiment, three independent experiments) from different fields of view. Black colored lines in the scatter plot represent the mean \pm SD, ${ }^{\star \star \star \star} p$-value (one-way ANOVA) $<$ 0.0001 versus negative control (GFP-vector/PP1 $)$ ). e-f Single-molecule coincidence detection between GFP-PP1 $\alpha$ and $\mathrm{mCherry-Cavin1} \mathrm{(e)} \mathrm{or} \mathrm{mCherry-}$ Cavin3 (f). Coincidence ratio value $(C)=$ intensity $(A 549 \mathrm{~nm}) /$ total intensity

microscopy revealed a loss of morphological caveolae (caveolae per length of plasma membrane of cells incubated in hypoosmotic medium, $65.5 \pm 8 \%$ of iso-osmotic treated A431 cells; Supplementary Fig. 6). We then used PLA to assess interaction of endogenous Cavin 1 and Cavin3 and PP1a (Fig. 4c). The interaction between Cavin1 and Cavin 3 was used as a positive control, with fluorescent puncta indicating interaction observed along the plasma membrane of these cells. In contrast, endogenous cavins and PP1 $\alpha$ were not in close proximity and few PLA puncta were observed in untreated cells (Fig. 4c-e, upper panels; see PLA controls Supplementary Fig. 8), indicating few associations between PP1 $\alpha$ and Cavin 1 or Cavin3 under steady state in A431 cells. Upon hypo-osmotic treatment, there was a dramatic increase in association of endogenous PP1a, and Cavin1 or Cavin3 (a fourfold increase in Cavin1-PP1a and a 2.6-fold increase in Cavin3-PP1a interactions; Fig. 4d and f; Fig. 4e and h). The ratio of nuclear and cytosolic localized interaction signals was calculated and revealed that the majority of Cavin1-PP1a (78.6 $\pm 6.9 \%$; Fig. $4 \mathrm{~g}$ ) and Cavin3-PP1a (73.9 $\pm 3.3 \%$; Fig. 4i) complexes formed after hypo-osmotic treatment were localized in the cytosol. Consistent with the quantitative data, the redistribution of PP1a from the nucleus to the cytosol, as well as the release of both Cavin 1 and Cavin3 from plasma membrane caveolae to the cytosol, was observed by immunofluorescence (Fig. 4a, b, lower panels). As in A431 cells, the redistribution of PP1a into the cytosol still occurred in cavin-deficient MCF-7 cells following 
a

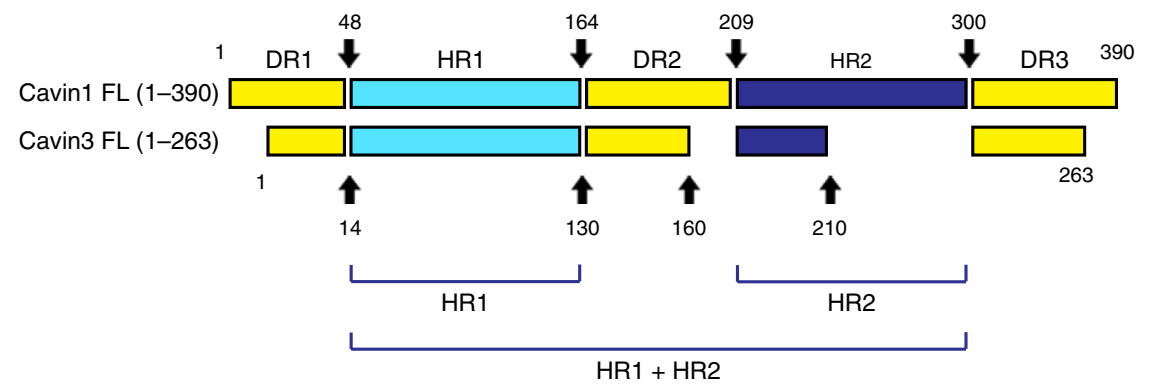

b

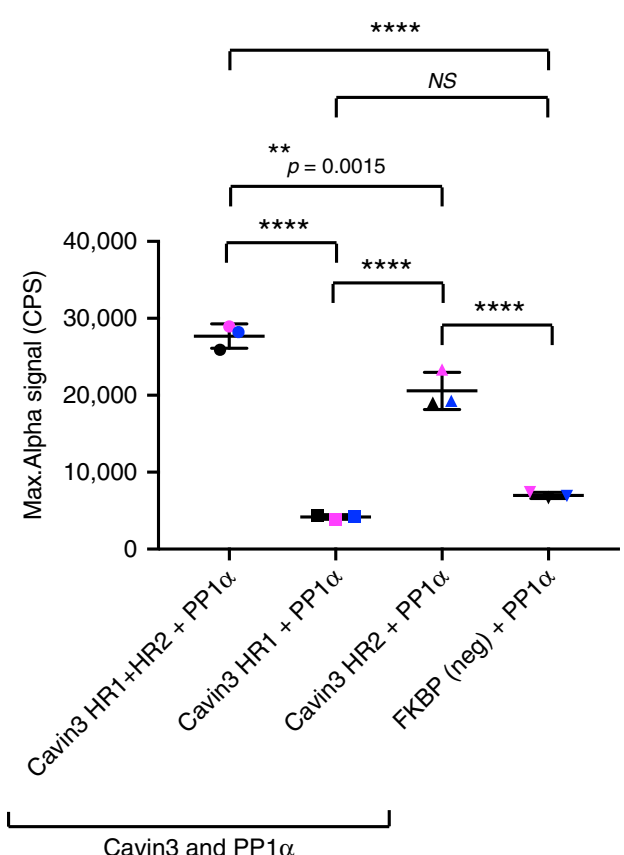

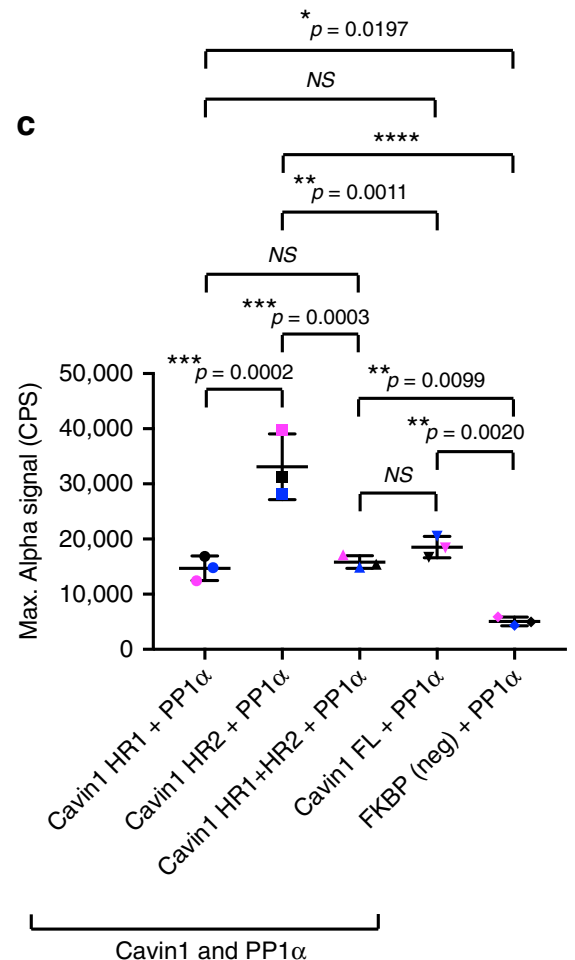

d
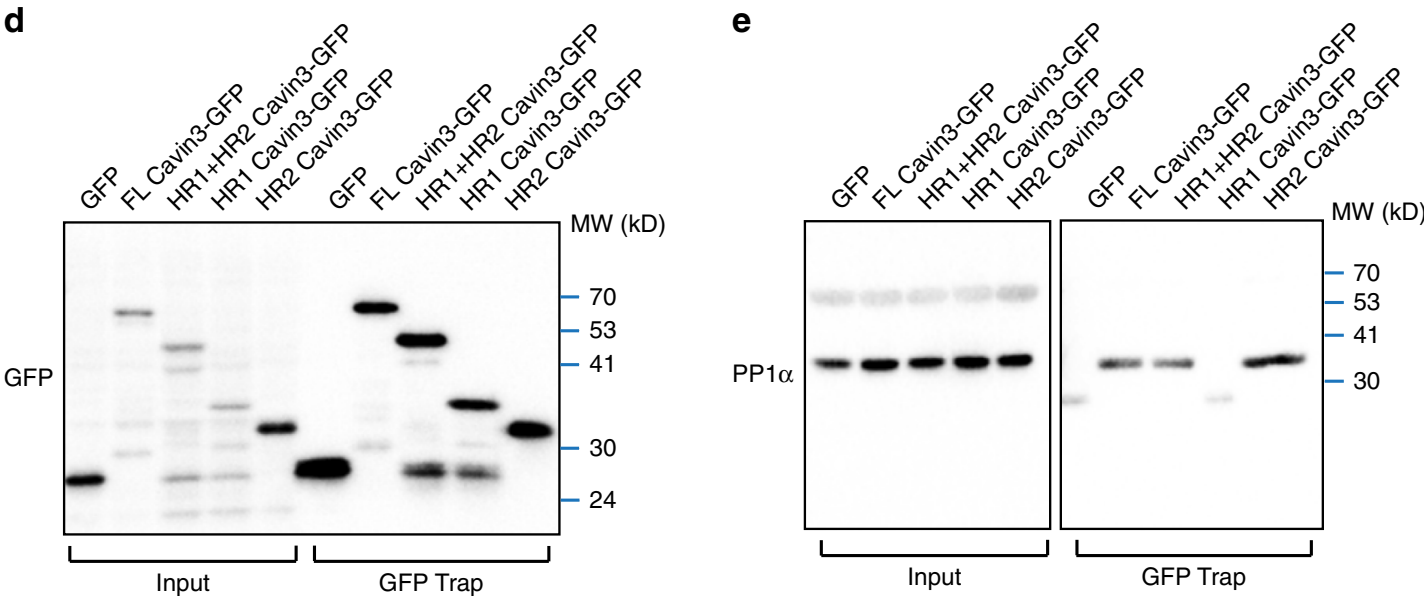

Fig. 3 PP1 $\alpha$ interacts with the HR2 domain of Cavin3 and Cavin1. a Schematic representation of the helical regions (HR) 1 and HR2 regions of Cavin1 and Cavin3. b AlphaLISA screen of Cavin3 HR1 domain, Cavin3 HR2 domain, and Cavin3 HR1+HR2 domain and PP1 $\alpha$, FKBP, and PP1 $\alpha$ (negative control), ${ }^{\star \star} p$ value $<0.01,{ }^{* \star *} p$-value $<0.0001$ (one-way ANOVA). NS = no significance. Scatter dots in each group represent the values from three independent experiments (labeled by three colors). c AlphaLISA screen of Cavin1 HR1 domain and PP1 $\alpha$, Cavin1 HR2 domain and PP1 $\alpha$, Cavin1 HR1+HR2 domain and PP1 $\alpha$, Cavin1 FL and PP1 $\alpha$, and FKBP and PP1 $\alpha$ (negative control), ${ }^{\star} p$-value $<0.05,{ }^{\star \star} *$-value $<0.01,{ }^{\star \star \star} p$-value $<0.001,{ }^{\star \star \star *} p$-value $<0.0001$ (one-way ANOVA). Mean \pm SD are presented for three sets of experiments. d-e GFP-tagged full-length Cavin3 (lane 2) and truncation mutants (HR1+HR2) domain, HR1 domain or HR2 domain were expressed in MCF-7 cells followed by lyzed GFP Trap pulldown assays. Transfection and pulldown efficiency were examined by western blot analysis using anti-GFP antibodies (d). Endogenous PP1 $\alpha$ (e) was detected by western blotting using PP1 $\alpha$ specific antibodies. Results are representative of three independent experiments 
a

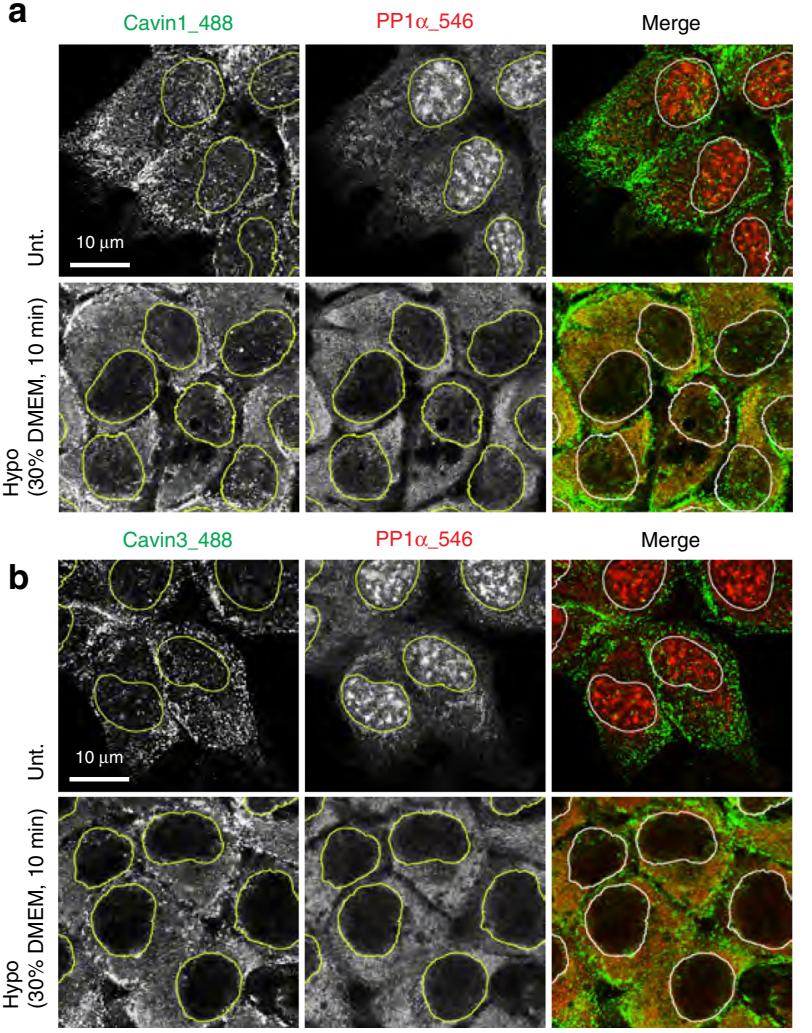

j

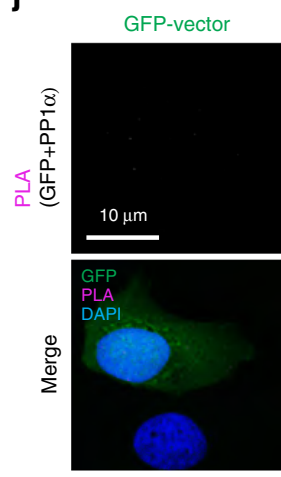

Cavin1-GFP
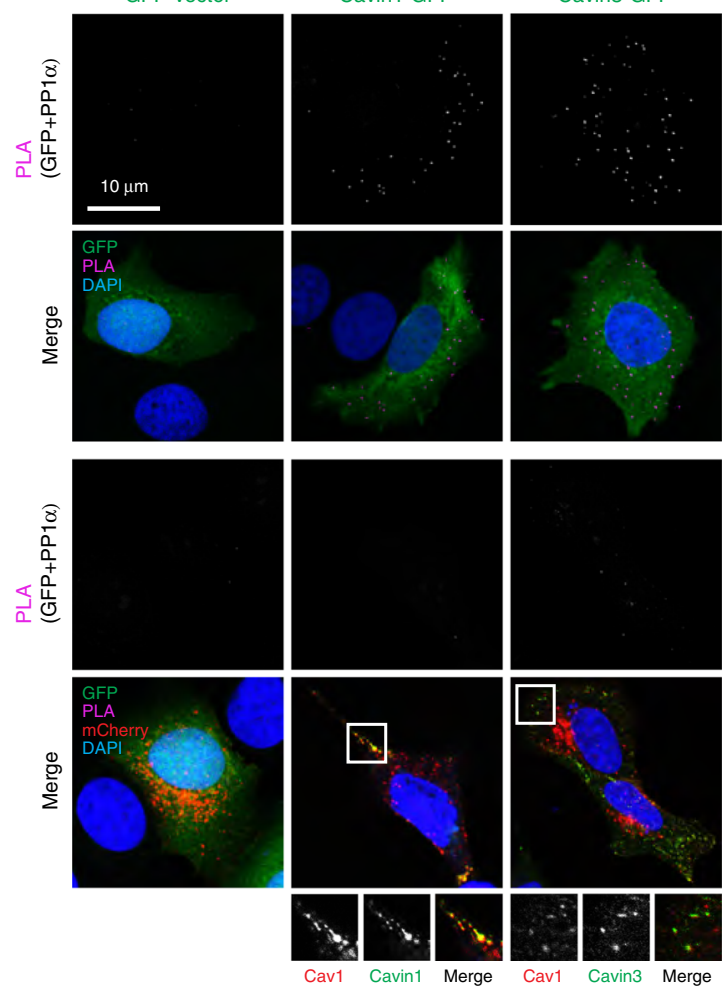

e

PLA signal/DAPI

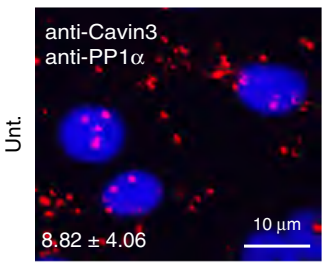

PLA signal/DAPI/DIC
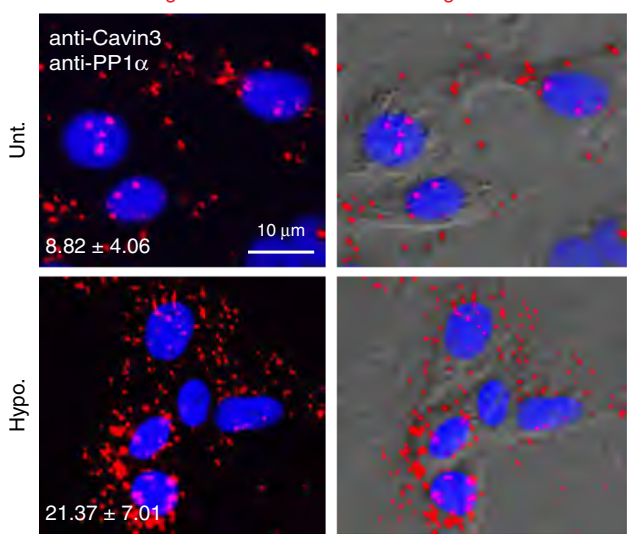

h

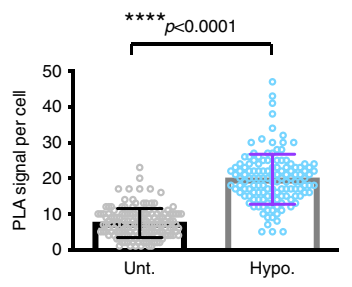

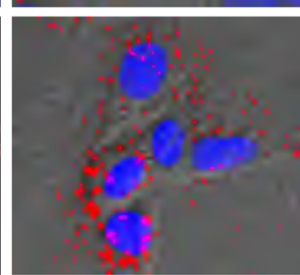

i PLA signal per cell

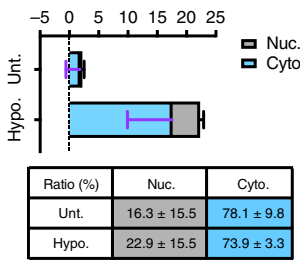

hypo-osmotic treatment, suggesting that hypo-osmotic stressinduced translocation of PP1 $\alpha$ is a cavin/caveolae-independent process (Supplementary Fig. 7).

These results strongly suggest that the release of cavins is required for association with PP1a. To further test this, we expressed GFP-tagged Cavin 1 and 3 with PP1 $\alpha$ in MCF-7 cells with or without the co-expressed caveola forming proteins, CAV1 and Cavin1 (Fig. 4j). Cavin1-GFP or Cavin3-GFP alone showed cytosolic distribution (Fig. 4j, upper two panels).
With the addition of Flag-Cavin1 (except for Cavin1-GFP expressing cells) and mCherry-CAV1 (Fig. 4j, lower two panels), Cavin1-GFP and Cavin3-GFP were recruited to caveolae, whereas a negative control GFP-vector remained in the cytosol. PLA signals for the association of PP1a and GFPtagged Cavin 1 or Cavin3 were downregulated in caveolarescued MCF-7 cells (Fig. 4j, lower two panels), suggesting that the sequestration of cavins at caveolae abolishes their interaction with PP1a. 
Fig. 4 Hypo-osmotic interactions of endogenous PP1 $\alpha$ and cavin proteins. a, b Representative immunofluorescence images of endogenous Cavin1 (green) and PP1 $\alpha$ (red) (a) or Cavin3 (green) and PP1 $\alpha$ (red) (b) in untreated or hypo-osmotic treated A431 cells. Yellow or white circles (in merged images) indicate the outline of the nucleus. Scale bar, $10 \mu \mathrm{m}$. Images are representative of three independent experiments. c Representative images of PLA signals (red)/cell representing the interactions of endogenous PP1 $\alpha /$ Cavin1 or PP1 $\alpha /$ Cavin3 in A431 cells from three independent experiments. Cavin1/Cavin3 interaction was used as a positive control. DAPI was used to visualize nuclear DNA (blue). Scale bar, $10 \mu \mathrm{m}$. d, e PLA signal/cell of Cavin1/PP1 $\alpha$ and Cavin3/PP1 $\alpha$ interactions in A431 cells with or without hypo-osmotic treatment. The PLA signals between cells were distinguished by the matched DIC microscopy and are represented as the mean \pm SD. Scale bar, $10 \mu \mathrm{m}$. f, h Quantitation of PLA signals for the Cavin1/PP1 $\alpha(\mathbf{f})$ and Cavin3/PP1 $\alpha(\mathbf{h})$ interactions upon hypotonic treatment, $n=150$ cells for three independent experiments. ${ }^{\star \star \star \star} p$-value (Student's $t$-test, two tail) $<0.0001$. $\mathbf{g}$, $\mathbf{i}$ The number and ratio (\%) of nuclear (Nuc.) and cytoplasmic (Cyto.) localized PLA signal for Cavin1/PP1 $\alpha$ (g) and Cavin3/PP1 $\alpha$ (i) interactions was quantified using CellProfiler, where DAPI staining was utilized for nuclear identification. Histogram represents the mean \pm SD values of PLA signal number in each cell from three independent experiments ( $n=50$ cells for each experiment). Cytoplasmic and nuclear signals were labeled as blue and gray. The values of the ratio are presented in in the table as mean \pm SD. $\mathbf{j}$ MCF-7 cells transfected with GFP-cavins and GFP-vector (upper two panels), or with additional mCherryCAV1 and Flag-Cavin1 (not expressed in Cavin1-GFP cells) (lower two panels). PLA signals for the interaction between GFP and PP1 $\alpha$ were detected and visualized as magenta puncta in merged images. PLA signal images alone were inverted to gray scale. Enlarged images showing the colocalization between mCherry-CAV1 and GFP-tagged Cavin1 and Cavin3 are presented. Scale bar, $10 \mu \mathrm{m}$. Images are representative of three independent experiments

Cavin3 and PP1a interact in response to UV stress. Having established a sensitive assay for cavin-PP1a association, we next asked whether other stimuli could similarly induce caveolar disassembly and facilitate the interaction between Cavin3 and PP1a. We focused on Cavin 3 and its response to UV since its expression has been demonstrated to increase cellular sensitivity of cells to various stressors ${ }^{31,32}$. We first treated A431 cells with UV (2 min treatment and further $4 \mathrm{~h}$ incubation) that induced significant redistribution of Cavin3 from the plasma membrane to the cytosol and nucleus and colocalization with PP1 $\alpha$ (Supplementary Fig. 10a). We next used PLA to detect co-association of endogenous Cavin 3 and PP1a. As shown in Fig. 5a (quantification in Fig. 5b, also see PLA controls in Supplementary Fig. 8c), a significant increase in the interaction of PP1 $\alpha$ and Cavin3 after UV treatment (Fig. 5b) was observed mainly in the nucleus $(66.1 \pm$ $2.0 \%$; Fig. $5 \mathrm{c}$ ) of these cells. Moreover, an increase in the interaction of Cavin3 with PP1a after UV treatment of A431 cells was also detected using a GFP Trap pulldown approach (Supplementary Fig. 10b). Consistent with a model in which caveolar disassembly is required for cavin release from caveolae, morphologically recognizable caveolae were consistently reduced in UV-treated cells (density of apical caveolae $60 \pm 11 \%$ (SEM) of control cells; Fig. 5d).

To test whether other cell types show a similar UV-mediated redistribution of Cavin 3 to allow interaction with PP1 $\alpha$, we tested the effect of UV treatment on the MDA-MB-231 cells that demonstrated a similar increased interaction between Cavin 3 and PP1a in both the cytosol and nucleus following UV treatment (Supplementary Fig. 9). Collectively, these results suggest that the redistribution of Cavin3 and interaction with PP1a is a general response to UV-induced stress.

Cavin3 interacts with PP1a to regulate UV apoptosis. We next hypothesized that the induced interaction between Cavin3 and PP1a might influence a UV-induced downstream cellular response. UV stress causes DNA damage and drives signaling pathways that determine cell fate, DNA damage-induced cell death or survival ${ }^{33,34}$. We depleted A431 cells of PP1a or Cavin3, respectively, using an siRNA-approach and measured the activation of DNA damage response proteins. We first assessed the phosphorylation of $\mathrm{H} 2 \mathrm{AX}$, termed $\gamma \mathrm{H} 2 \mathrm{AX}$, as a DNA damage marker ${ }^{35,36}$. $\gamma \mathrm{H} 2 \mathrm{AX}$ levels were increased in PP1a-depleted A431 cells (Fig. 5e, quantification in Fig. 5f, panel i). In contrast, $\gamma \mathrm{H} 2 \mathrm{AX}$ levels were significantly reduced in Cavin3-depleted A431 cells (Fig. 5e, quantification in 5f, panel i). These results suggested that Cavin3 and PP1a play opposite roles in DNA damage signaling as measured by $\mathrm{H} 2 \mathrm{AX}$ phosphorylation. Furthermore, in the absence of PP1a, Cavin3 depletion (cells with
PP1a-siRNA and Cavin3-siRNA knockdown) showed no significant effect on the generation of $\gamma \mathrm{H} 2 \mathrm{AX}$ following UV irradiation compared with control cells (scrambled siRNA) (Fig. 5e, quantification in $5 \mathrm{f}$, panel i), indicating that Cavin3-mediated UV responsive regulation on $\gamma \mathrm{H} 2 \mathrm{AX}$ is $\mathrm{PP} 1 \alpha$ dependent. These findings were further confirmed in reciprocal PP1 $\alpha$ and Cavin3 overexpression experiments (Supplementary Fig. 10c, quantification in Supplementary Fig. 10d).

These findings led us to directly test whether the Cavin3-PP1a system regulates apoptosis. We immunoblotted for cleavedcaspase-3 and cleaved PARP, classical apoptosis markers (Fig. 5g). Similar to $\gamma \mathrm{H} 2 \mathrm{AX}$ protein levels, cleaved-caspase- 3 and PARP were both decreased in Cavin3-depleted A431 cells and upregulated in PP1a-depleted A431 cells after UV treatment compared with control treated cells (Fig. $5 \mathrm{~g}$, quantification in Fig. 5h). In addition, these apoptotic markers showed no significant difference in cells with double knockdown of PP1a and Cavin3 compared with control cells (scrambled siRNA) (Fig. 5g, quantification in 5h). Reciprocal results were observed in A431 cells overexpressing Cavin3 or PP1a, respectively (Supplementary Fig. 10e, quantification in Supplementary Fig. 10f). These data further suggested that PP1a is a major intracellular target for Cavin3 in the regulation of UV-induced apoptosis. As an independent validation of the western analysis, we measured $\mathrm{LDH}$ release as an index of plasma membrane damage in cells after UV treatment. LDH release after UV treatment was increased in PP1a-depleted A431 cells and decreased in Cavin3-depleted A431 cells (Fig. 5i). Simultaneous knockdown of both PP1a and Cavin3 in A431 cells slightly neutralized the effect of PP1a depletion on LDH release in these cells (Fig. 5h). These findings were further confirmed in reciprocal overexpression experiments (Supplementary Fig. 10g). Simultaneous overexpression of both PP1a and Cavin3 in A431 cells restored LDH release after UV treatment to control levels (Supplementary Fig. $10 \mathrm{~g}$ ). Collectively, these data suggest that interaction with PP1a is crucial for released Cavin3 to promote apoptosis following UV treatment.

Cavin3 attenuates PP1a activity and promotes H2AX phosphorylation. PP1a modulates signaling pathways by dephosphorylating its substrates ${ }^{37-39}$. Our experiments demonstrated that PP1 $\alpha$ negatively regulates the phosphorylation of $\mathrm{H} 2 \mathrm{AX}$ in response to $\mathrm{UV}$-induced DNA damage raising the possibility that $\gamma \mathrm{H} 2 \mathrm{AX}$, may be a substrate of PP1a.

To test this, we first examined the levels of $\gamma \mathrm{H} 2 \mathrm{AX}$ levels in A431 cells treated with tautomycin (TTM), a selective inhibitor of PP $1 \alpha^{40}$. As shown in Fig. 6a, the generation of $\gamma \mathrm{H} 2 \mathrm{AX}$ upon UV irradiation was significantly upregulated in TTM treated cells 
a
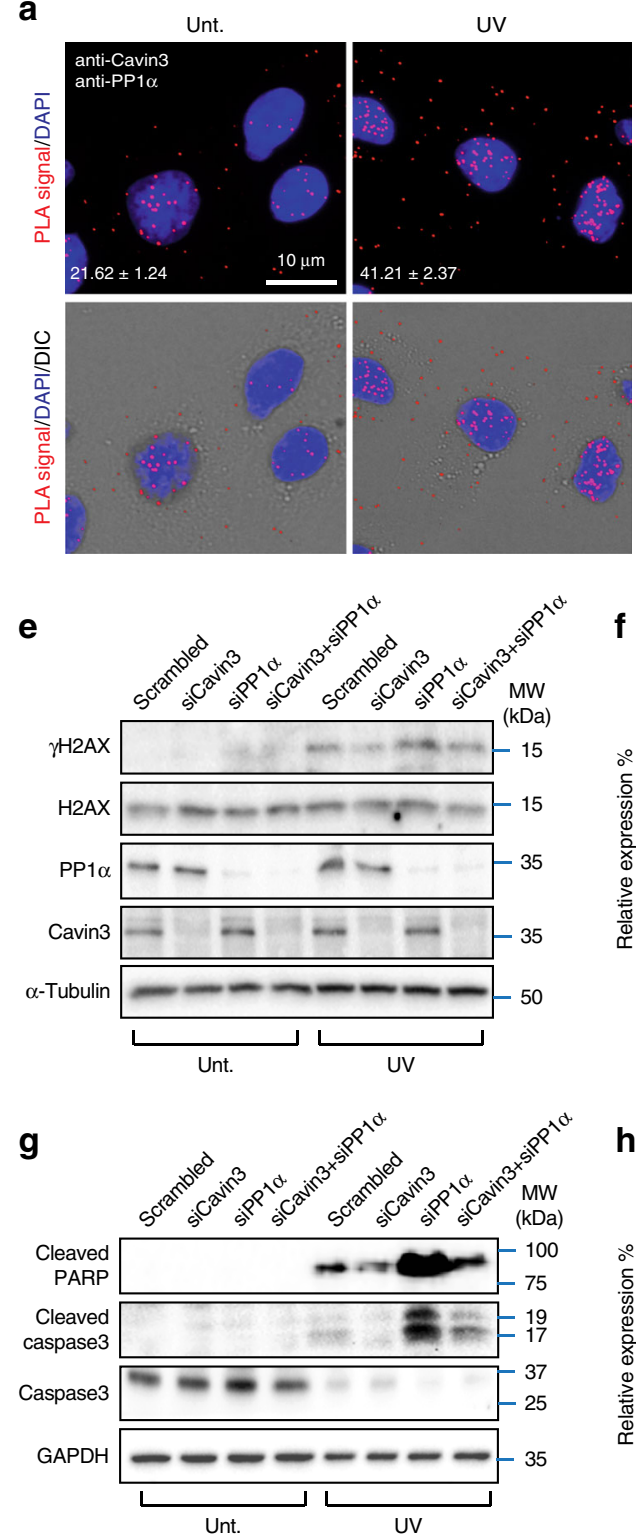

f

$\mathbf{h}$ b

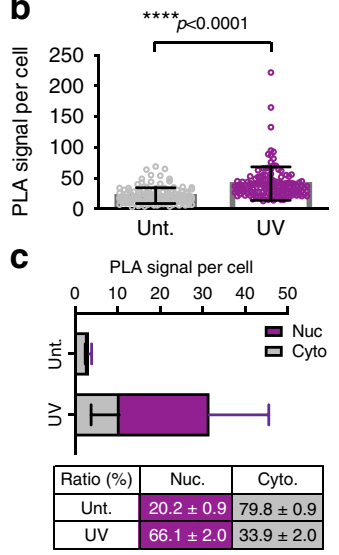

d

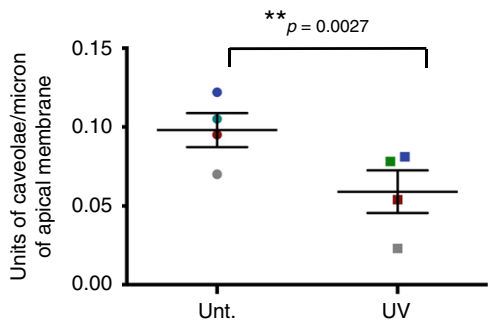

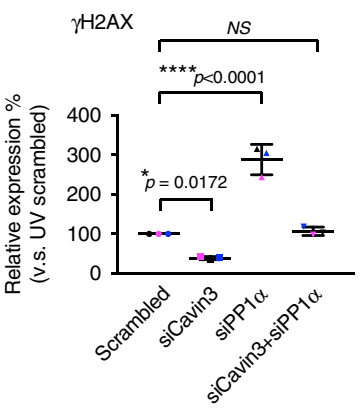
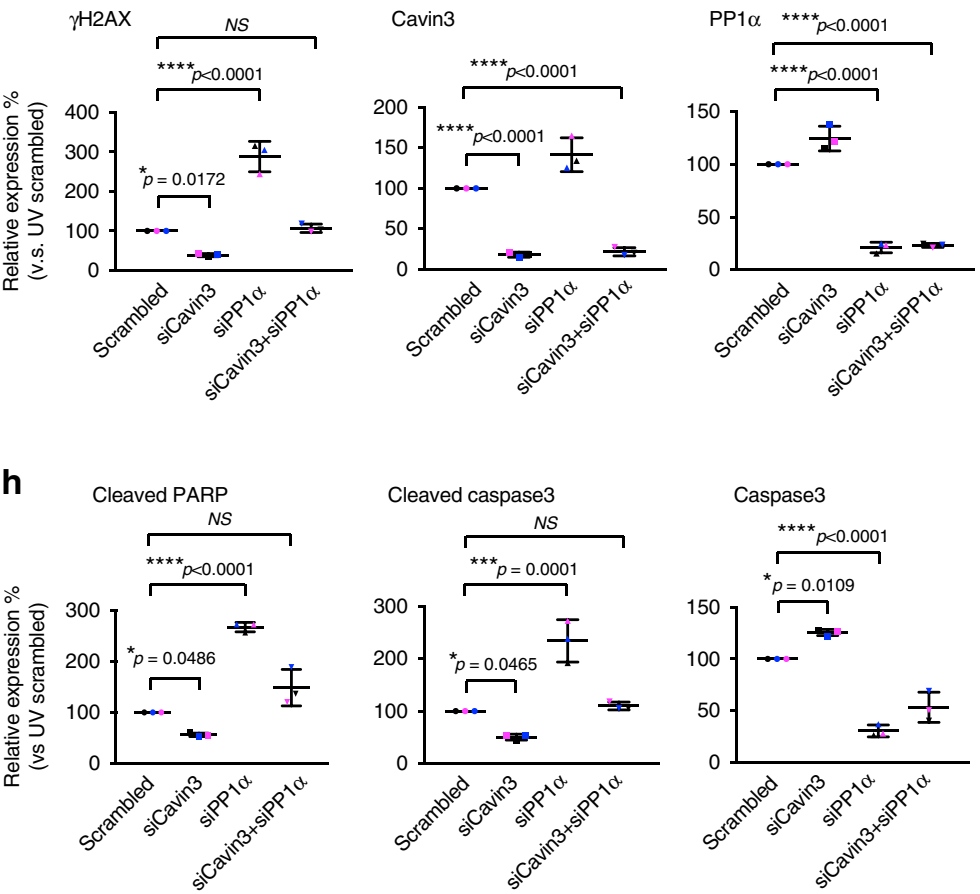

i

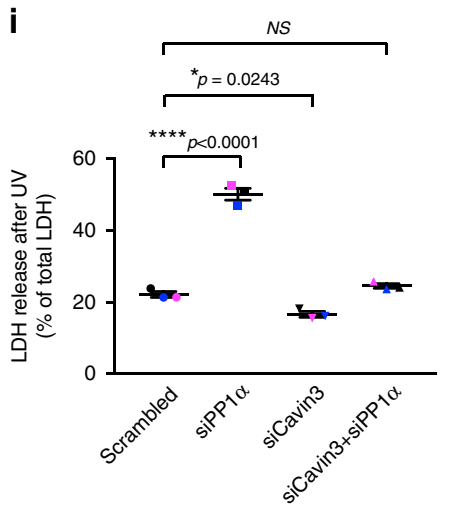

(quantification in Fig. 6b), suggesting that PP1a phosphatase activity contributes to the dephosphorylation of $\gamma \mathrm{H} 2 \mathrm{AX}$ upon UV treatment. We further examined whether Cavin 3 and PP1 1 form a complex with $\gamma \mathrm{H} 2 \mathrm{AX}$ using a GFP Trap pulldown in control or UV-treated A431 cells transfected with PP1a-GFP or Cavin3GFP. $\gamma \mathrm{H} 2 \mathrm{AX}$ was specifically coprecipitated by either PP1 $\alpha$-GFP or Cavin3-GFP only in response to UV treatment suggesting the formation of a UV-induced complex between these proteins (Fig. 6c, d). PLA further confirmed a predominant nuclear association of endogenous $\gamma \mathrm{H} 2 \mathrm{AX}$ and PP1 $\alpha(82.3 \pm 8.6 \%$; Fig. 6e, $\mathrm{f}$ ), as well as $\gamma \mathrm{H} 2 \mathrm{AX}$ Cavin $3(83.5 \pm 1.5 \%$; Fig. $6 \mathrm{~g}, \mathrm{~h})$, specifically after UV treatment. 
Fig. 5 PP1 $\alpha$-Cavin3 complex in UV-induced DNA damage response. a PLA interaction between Cavin3 and PP1 $\alpha$ upon UV treatment. DAPI detects the nucleus (blue). b Quantification of PLA Cavin3/PP1 $\alpha$ interactions in control and UV-treated cells as the mean \pm SD, three individual experiments. ${ }^{\star \star \star \star} p$ value (Student's $t$-test, two tail) < 0.0001. c The number and ratio of nuclear (Nuc.; purple) and cytoplasmic (Cyto.; gray) localized PLA signals for Cavin3PP1 $\alpha$ interactions presented as mean \pm SD, three independent experiments in a histogram and table. $\mathbf{d}$ Quantitation of caveolae number in untreated and UV-treated A431 cells. Caveolae number on the apical surface from four sets of images were quantified blinded from three independent experiments and were normalized to the length of the surface sampled (over $150 \mu \mathrm{m}$ for each set of images where ${ }^{\star \star} p=0.0027$, Student's $t$-test, two tail). e A431 cells transfected with scrambled siRNA (control), Cavin3 and PP1 $\alpha$ individually or together were exposed to UV treatment. Lysates were western blotted for $\gamma \mathrm{H} 2 \mathrm{AX}$ and $\mathrm{H} 2 \mathrm{AX}$ anti-PP1 $\alpha$ and anti-Cavin3 and $\alpha$-Tubulin antibodies. f Relative protein expression (\%) of $\gamma \mathrm{H} 2 \mathrm{AX}$ (Scrambled vs siCavin3: ${ }^{*} p=0.0172$, Scrambled vs siPP1: ${ }^{\star \star \star \star} p<0.0001$ ), Cavin3 (Scrambled vs siCavin3: ${ }^{\star \star \star \star} p<0.0001$, Scrambled vs siCavin3+siPP1: $\left.{ }^{* \star \star *} p<0.0001\right)$, and PP1 $\alpha($ Scrambled vs siPP1: ${ }^{\star \star \star \star} p<0.0001$, Scrambled vs siCavin3+siPP1: $\left.{ }^{\star \star \star} p<0.0001\right)$, three independent experiments, one-way ANOVA with a Tukey's multiple comparison test. $\mathbf{g}$ Western blot analysis of cleaved PARP, cleaved-caspase-3, total caspase-3 and GAPDH in PP1 $\alpha-$ or/and Cavin3-knockdown A431 cells. h Relative protein expression (\%) of cleaved PARP (Scrambled vs siCavin3: ${ }^{\star} p=0.0486$, Scrambled vs siPP1: ${ }^{\star \star \star \star} p<0.0001$ ), cleaved caspase-3 (Scrambled vs siCavin3: ${ }^{\star} p=0.0465$, Scrambled vs siPP1: ${ }^{\star \star \star} p=0.0001$ ) and total caspase-3 (Scrambled vs siCavin3: ${ }^{\star} p=0.0109$, Scrambled vs siPP1: $\left.{ }^{\star \star \star \star} p<0.0001\right)$. Three independent experiments analyzed using one-way ANOVA. i LDH release (\% of total LDH) was calculated (Scrambled vs siPP1: ${ }^{\star \star \star \star} p<0.0001$, Scrambled vs siCavin3: ${ }^{\star} p=0.0243$ ). Significance was determined by one-way ANOVA and a Bonferroni test from three independent experiments

Taken together, our results suggest that Cavin3 and PP1a form a complex (Fig. 5a-c; Supplementary Fig. 8b) and exhibit opposite effects on UV-induced H2AX phosphorylation (Fig. 5e-f; Supplementary Fig. 10c, d). These results suggest Cavin3, as a PP1a interacting protein, may possess regulatory effects on PP1a that impact H2AX phosphorylation. To test this idea, the effect of Cavin 3 on the phosphatase activity of PP1a was assessed using a phosphatase assay. PP1a was immunoprecipitated from MCF-7 cells with or without Cavin3 re-expression to exclude the impact of other phosphatases. Overexpression of $\mathrm{mScarlet}-\mathrm{PP} 1 \alpha$, a positive control, showed significantly increased phosphatase activity compared with MCF-7 cells with endogenous PP1a expression (Fig. 6i). Cavin3 re-expression in MCF-7 cells significantly downregulated the phosphatase activity of both endogenous and overexpressed PP1 $\alpha$ (Fig. 6i), suggesting Cavin3 negatively regulates PP1 $\alpha$ activity. Collectively, our results suggest that released Cavin3 from caveolae plays an important proapoptotic role in UV treatment through interaction with and inhibition of PP1a. Considering the opposing roles of Cavin3 and PP1a in apoptosis and the functions of PP1a in facilitating DNA repair, we propose that the Cavin3-PP1 $\alpha$ complex affects UV-induced DNA damage signaling by directly interacting with $\gamma \mathrm{H} 2 \mathrm{AX}$ and by competitively modulating the phosphorylation level of $\gamma \mathrm{H} 2 \mathrm{AX}$ (Fig. 7).

\section{Discussion}

This report describes a number of complementary approaches; BioID, GFP Trap/MS, ALPHAScreen and PLA as effective methods to screen for proximate and interacting partners of intracellular localized cavin proteins. The power of our experimental approach is the identification of potential interacting proteins by heterologous expression in a cell line lacking caveolar proteins and in vitro ALPHAScreen in addition to detailed studies to validate the interaction of cavins and PP1a. These approaches (ALPHAScreen, BioID and GFP Trap/MS) have differing advantages/disadvantages for protein identification. GFP Trap pulldowns identified cavin complexes but may miss low affinity or transient interactions, whereas BioID requires biotinylation in a correct spatial proximity (estimated to be around 10 $\mathrm{nm}$ ) with the advantage of labeling physiological interactions in live cells even when these are very weak or transient in nature ${ }^{41}$. In addition, ALPHAScreen in combination with in vitro synthesized cavins, is a sensitive, high throughput, systemic way to evaluate direct protein-protein interactions.

Our results show that cellular stress can cause release of cavins from plasma membrane caveolae suggesting that cavin proteins act as intracellular signaling molecules. The results of this study have general significance for a mechanistic understanding of caveola function. Caveolae are the most abundant surface organelle of many human cells and yet we still have no clear understanding of how caveolae function in healthy cells and the implications of caveolar dysfunction in numerous diseases with which caveolae have been linked. Our working hypothesis is that cavin proteins may be the key to understanding the multiple cellular pathways linked to caveolae. Previous studies have demonstrated that caveolae can be disassembled to release cavin proteins as distinct subcomplexes into the cytosol comprising Cavin1/Cavin2, Cavin1/Cavin3, and monomeric Cavin $3^{8,9}$ in response to increased membrane tension and independently, Cavin1 can be released from surface caveolae in response to insulin treatment of adipocytes allowing interaction with nuclear targets $^{42}$. Our data now show that caveolae can also release cavins in response to "non-mechanical" stressors such as UV and can be considered as more general stress sensors. In addition, our previous studies have uncovered a pathway that maintains low cytosolic cavin protein levels under steady state conditions, a prerequisite for a signaling pathway dependent on cytosolic cavin proteins ${ }^{43}$.

Furthermore, a number of different intracellular locations for the cavins (including association with the nucleus) have been described by us and others ${ }^{42,44}$ which may indicate that these proteins interact with other intracellular compartments when released from caveolae. This is supported by the majority of proteins identified as potential non-caveolar cavin-interacting proteins being localized predominantly in the cytosol and nucleus that may be relevant to disease conditions. Cavin proteins are strongly linked to cancer ${ }^{45-48}$ and it will be important to determine if the links to stress $^{48}$ and to metabolism ${ }^{13}$ are related to changes in cavin expression and localization in cancer cells (discussed further in Supplementary Information section).

Using our interaction analyzes, we identify PP1a as an intracellular target for Cavin3 when released from caveolae in response to UV stress. We propose that the interaction between Cavin3 and PP1a influences UV-mediated apoptosis through the formation of a complex with $\gamma \mathrm{H} 2 \mathrm{AX}$, where PP1 $\alpha$ acts to inhibit $\gamma \mathrm{H} 2 \mathrm{AX}$ phosphorylation resulting in a reduction in apoptosis while Cavin 3 acts to partially counteract PP1a functions during this nuclear event. Interestingly, Cavin3-PP1 $\alpha-\gamma \mathrm{H} 2 \mathrm{AX}$ complexes appear more concentrated in the nucleus (Fig. 6e, f) than Cavin3PP1 a complexes after UV treatment (Fig. 5a). This suggests that the formation of Cavin3-PP $1 \alpha-\gamma \mathrm{H} 2 \mathrm{AX}$ complex could be a dynamic process, whereby the released Cavin 3 may interact with the cytosolic pool of PP1a first and subsequently translocate into 
a

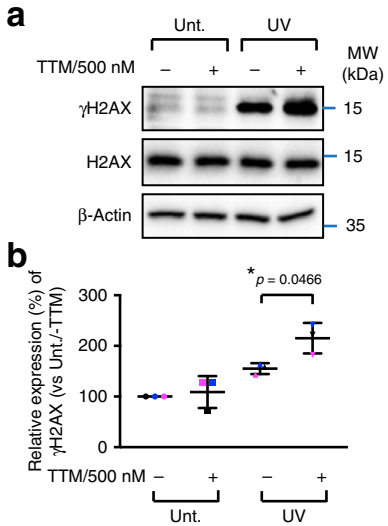

C

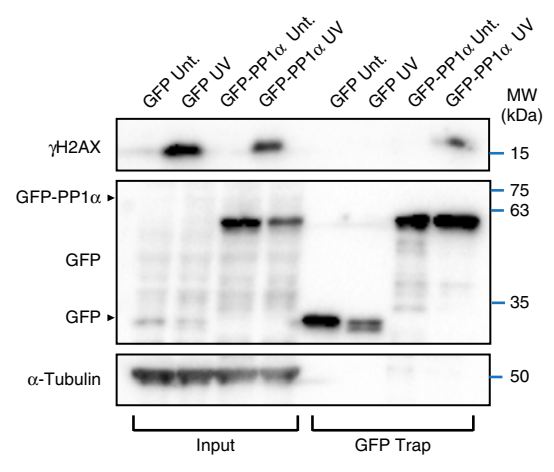

d

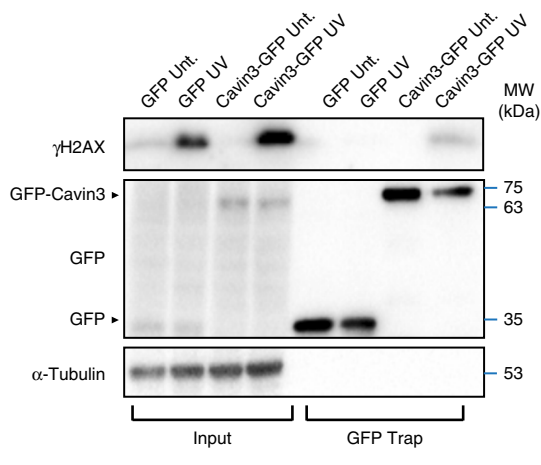

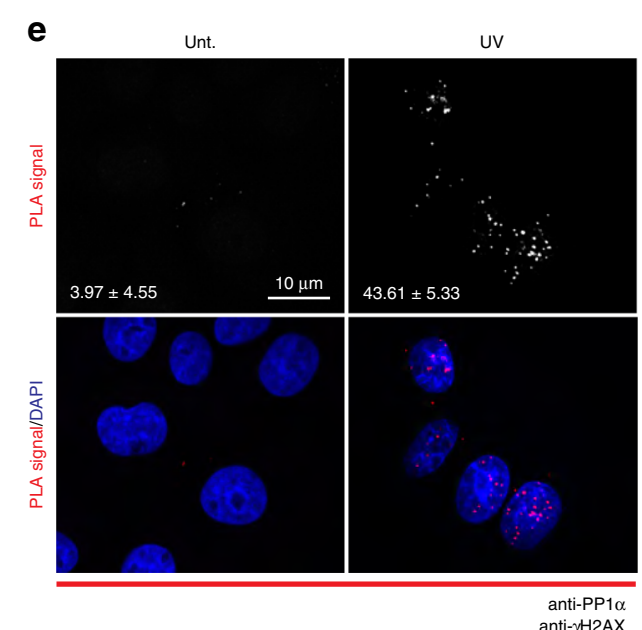

f

$\mathbf{f}$

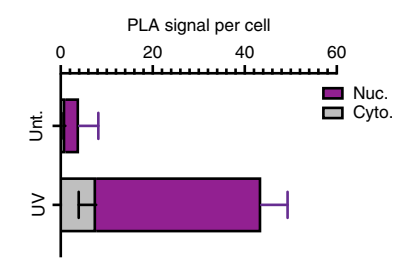

g
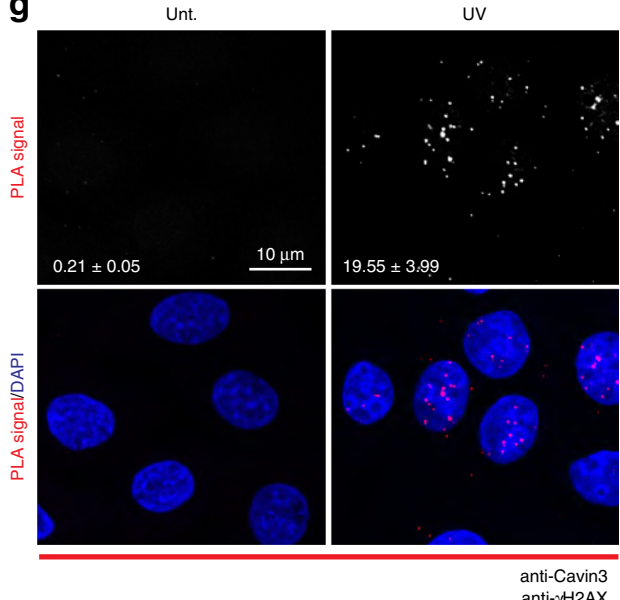

h

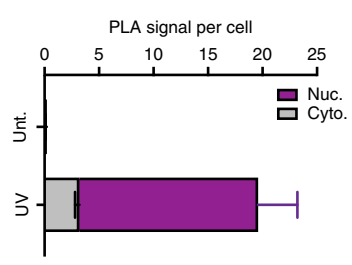

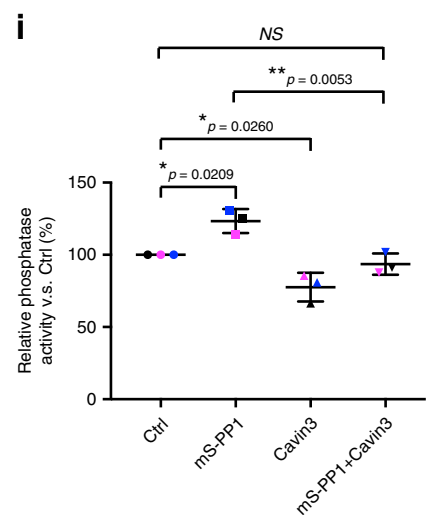

the nucleus as a Cavin3-PP1 $\alpha$ complex to associate with $\gamma \mathrm{H} 2 \mathrm{AX}$ (Fig. 7). Future experimentation will be required to elucidate the precise sequence of events leading to the formation of the cytoplasmic Cavin3-PP1a complex and the nuclear Cavin3-PP1a$\gamma \mathrm{H} 2 \mathrm{AX}$ complex. However, we believe that the differential distribution of Cavin3, PP1 $\alpha$ or Cavin3-PP1a complexes under hypo-osmotic treatment and UV stress is independent of $\gamma \mathrm{H} 2 \mathrm{AX}$ as $\gamma \mathrm{H} 2 \mathrm{AX}$ is also induced in the nucleus in response to hypoosmotic treatment ${ }^{49}$ yet Cavin3-PP1a complex is mainly cytosolic (Fig. 4e, h, i). 
Fig. $6 \gamma \mathrm{H} 2 \mathrm{AX}$ coprecipitates with PP1 $\alpha$ and Cavin3 following UV stress. a A431 cells were treated with tautomycin $(0.5 \mu \mathrm{M})$ for $3 \mathrm{~h}$ prior to UV irradiation. After a $4 \mathrm{~h}$ chase, cells extracts were western blotted for $\gamma \mathrm{H} 2 \mathrm{AX}$ and $\mathrm{H} 2 \mathrm{AX}$ levels. $\beta$-Actin was blotted as the loading control. $\mathbf{b} \gamma \mathrm{H} 2 \mathrm{AX}$ expression levels were quantified from three independent experiments where the data is presented as mean \pm SD. Unt $(-T T M): 100.0 \pm 0.0 \%$; Unt (+TTM): 155.1 $\pm 10.7 \%$; UV (-TTM): $108.8 \pm 31.5 \%$; UV (+TTM): $215.2 \pm 30.1 \%$ ) where ${ }^{\star} p=0.0466$ was calculated using an ordinary one-way ANOVA. c, d GFP Trap assays of A431 cells transfected with GFP-PP1 $\alpha$ or GFP (c), GFP-Cavin3 or GFP (d) followed by western bloting with an anti- $\gamma \mathrm{H} 2 \mathrm{AX}$ antibodies. Transfection efficiency was confirmed with GFP antibodies. $\alpha$-Tubulin was used as the loading control. e, $\mathbf{g}$ PLA of the interaction of endogenous PP1 $\alpha$ (e) or Cavin3 (g) with $\gamma \mathrm{H} 2 \mathrm{AX}$ upon UV radiation (shown as red dots). PLA signals alone were inverted to gray scale. Scale bar, $10 \mu \mathrm{m}$. Mean \pm SD from three independent experiments are presented on the images. $\mathbf{f}, \mathbf{h}$ The number and ratio of the PLA signals for PP1 $\alpha(\mathbf{f})$ or Cavin3 (h) with $\gamma \mathrm{H} 2 \mathrm{AX}$ in the cytoplasm (gray) and nucleus (purple) were calculated and presented in the histograms and tables as mean \pm SD from three independent experiments. $\mathbf{i}$ Phosphatase activity of PP1 $\alpha$ in MCF-7 cells with or without mScarlet-PP1 $\alpha$ (mS- PP1 $\alpha$ ) or/and pCB6-Cavin3 transfection. Relative phosphatase activity of control (\%) (Ctrl: 100.0 \pm 0.0\%; mS-PP1: $123.4 \pm 8.3 \%$; Cavin3: $77.6 \pm 10.0 \%$; mS-PP1+Cavin3: $93.5 \pm 7.4 \%$ ) is presented as the mean \pm SD from three independent experiments (Ctrl vs mS-PP1: ${ }^{\star} p=0.0209$, Ctrl vs Cavin3: ${ }^{\star} p=0.0260, \mathrm{mS}-\mathrm{PP} 1$ vs $\mathrm{mS}-\mathrm{PP} 1+$ Cavin3: ${ }^{\star \star} p=0.0053$ ) using an ordinary one-way ANOVA

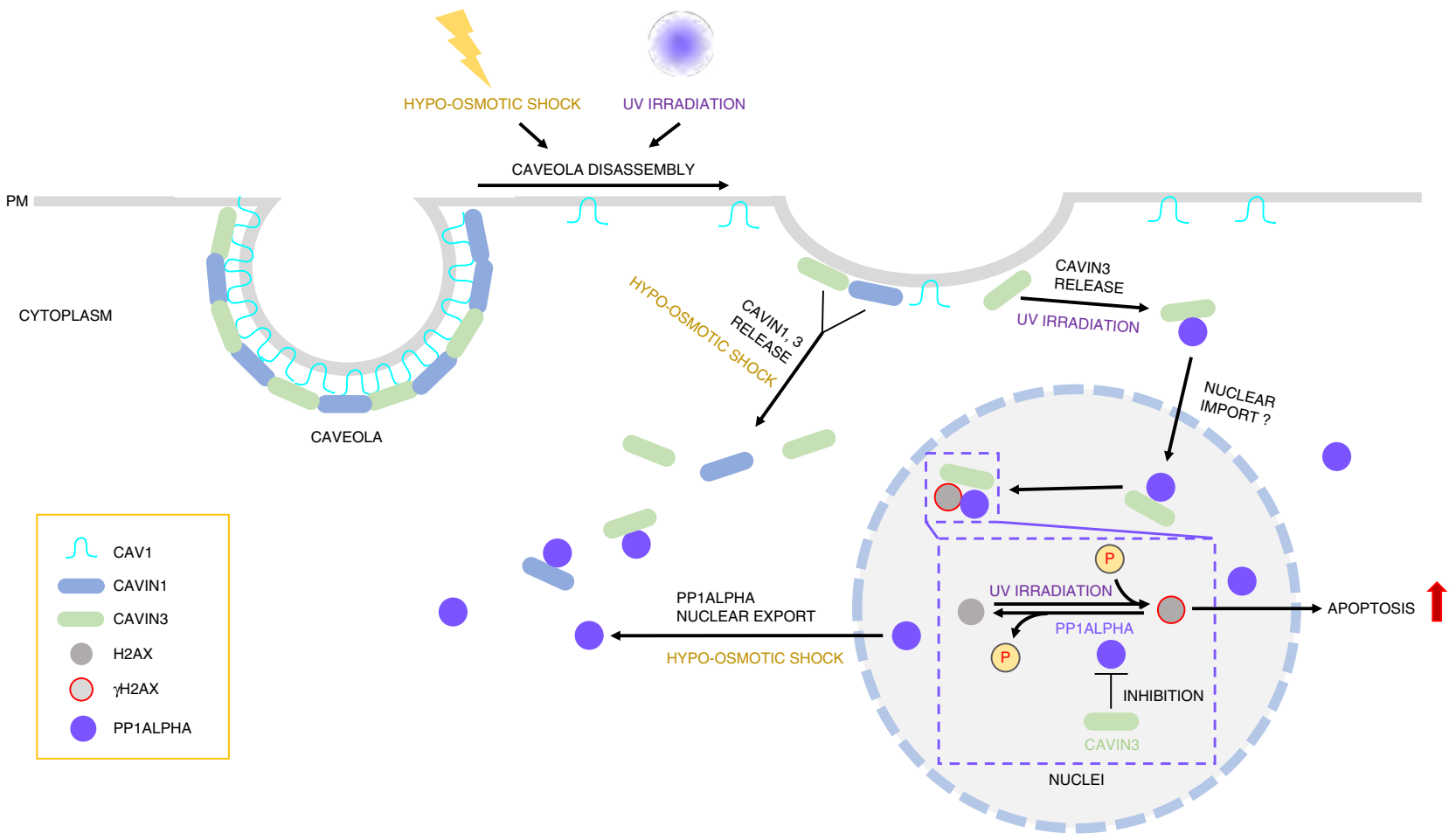

Fig. 7 Schematic of the interaction and function of cavins and PP1 $\alpha$ in response to stressors. In A431 cells (Cavin2-deficient), hypo-osmotic treatment induces redistribution of cavins and PP1 $\alpha$ to the cytosol from plasma membrane caveolae and the nucleus, respectively, to allow interaction of these proteins. In addition, UV treatment led to the dissociation of Cavin3 from caveolae. We propose that the released Cavin3 may interact with the cytosol pool of PP1 $\alpha$ first and be subsequently recruited to the nucleus as Cavin3-PP1 $\alpha$ complex to associate with $\gamma \mathrm{H} 2 \mathrm{AX}$. In the nucleus, Cavin3 exerts a proapoptotic role by promoting $\mathrm{H} 2 \mathrm{AX}$ phosphorylation and its downstream apoptotic signaling through the interaction with and inhibition of PP1 $\alpha$, which has been identified as a direct phosphatase for $\gamma \mathrm{H} 2 \mathrm{AX}$ (phospho-H2AX) in this study

Furthermore, our studies reveal that interaction of cavins with PP1a can occur in response to different stimuli (hypo-osmotic versus UV treatment) to allow a cavin protein to interact in a quantitatively distinct manner with the same intracellular proteins. PP1 catalytic subunits typically combine with proteins that modulate their activity to direct them to distinct substrates ${ }^{50-52}$. More than 50 PP1-interacting proteins (PIPs) have been described. We now identify Cavin1 and Cavin 3 as PP1a-interacting proteins. However, amino acid sequence analysis of the HR2 domain of Cavin1 and Cavin 3 that was demonstrated to bind directly with PP1a, did not reveal an obvious PP1-binding consensus motif or SILK or MYPhoNE motif that plays an essential role in regulating PP1 activity ${ }^{53}$. Therefore, the modality of the interaction between the cavin proteins and PP1a remains to be determined.

Numerous reports have demonstrated involvement of PP1 $\alpha$ in apoptosis ${ }^{54-57}$ through interaction with Bad and Bcl- $2^{54}$. Conversely, Cavin 3 has also been shown to promote apoptosis ${ }^{13}$ by increasing the apoptotic response of tumor cells to various stressors $^{31,32}$. Our results suggest that Cavin 3 and PP1a play opposite roles in the DNA damage response that is correlated with their protein expression in a number of cancers. Cavin3 is absence or downregulated due to promoter methylation ${ }^{58-62}$, whereas PP1a is upregulated in hepatocellular ${ }^{63}$ and oral squamous carcinomas ${ }^{64}$. Collectively, our findings suggest that the interaction between proapoptotic Cavin3 protein, and antiapoptotic PP1a protein, is a death signal where further studies of this complex may provide insights into how cells evade apoptosis, an essential hallmark of cancer ${ }^{65}$.

Multiple phosphatases have been implicated in negatively regulating $\gamma \mathrm{H} 2 \mathrm{AX}$ with emerging data suggesting redundancy as well as context-dependent specificity. Phosphorylation of H2AX is a very early event in the DNA damage response required for the assembly of DNA repair proteins at sites of damaged chromatin. Double strand breaks (DSBs) are also formed in the course of 
DNA fragmentation in apoptotic cells ${ }^{66}$ specifically in the final stages of this process. In this context, Cavin3-PP1 $\alpha-\gamma \mathrm{H} 2 \mathrm{AX}$ complex may act as a scaffold in facilitating chromatin remodeling and damage responsive factors at the sites of DSBs in terminally apoptotic cells to regulate the removal of $\gamma \mathrm{H} 2 \mathrm{AX}$ from this site through dephosphorylation by PP1a. We hypothesize that non-caveolar Cavin3 may bind to PP1a to regulate its phosphatase activity and consequently adjust the balance between cell death and cell survival following DNA damage. Further work is required to characterize the specific physiological substrates and regulation of the complex formed between Cavin3-PP1a$\gamma \mathrm{H} 2 \mathrm{AX}$.

The cavin interaction network generated by this work will lead to further understanding of caveolar function. The identification of a vast array of non-caveolar cavin-interacting proteins has provided evidence for involvement of these proteins in diverse cellular processes, such as metabolism and stress-signaling, which could not have been envisaged even a few years ago. These results will now allow us to begin to understand the role of caveolae in numerous diseases including cancer and the role of caveolae in protecting cells against stress.

\section{Methods}

Reagents. Dulbecco's modified Eagle's medium (DMEM), glutamine, trypsinEDTA were from Sigma-Aldrich (Castle Hill, New South Wales, Australia). Penicillin/streptomycin was from Invitrogen (Carlsbad, CA, USA). Fetal bovine serum (FBS) was from Life Technologies (Melbourne, Victoria, Australia). Protease Inhibitor Cocktail Set III was from Merck Millipore (Darmstadt, Germany) and PhoSTOP Phosphatase Inhibitor Cocktail was from Roche Diagnostics Australia (Castle Hill, NSW, Australia). Tautomycin was from Enzo Life Science (ALX-380041-CO25, Michigan, USA).

Antibodies. The following antibodies were used: rabbit anti-CAV1 (dilution WB 1:3000) (610060, BD Biosciences, Franklin Lakes, New Jersey, USA), rabbit antiCavin 1 antibody were raised as described previously by ref. ${ }^{3}$ and was used for immunofluorescence (dilution IF/PLA 1:200), rabbit anti-Cavin3 (dilution WB 1:1000, IF/PLA 1:200) (16250-1-AP, ProteinTech Group, Chicago, IL, USA), rabbit anti-Cavin1 (WB 1:2000) (AV36965, Sigma-Aldrich, mouse antiPRKCDBP/Cavin3 (dilution IF/PLA 1:200) (HOO112464-MO4, Novus Biologicals, LLC, Littleton, CO, USA) (dilution IF 1:200), rabbit anti-PP1a-FL (dilution WB 1:1000, IF/PLA 1:100) (sc-443 Santa Cruz, Biotechnologies, Inc, Dallas, TX, USA), mouse anti-PP1 $\alpha$ (dilution WB 1:1000, IF/PLA 1:100) (G-4 71762, Santa Cruz, Biotechnologies), rabbit anti-cleaved caspase-3 (Asp175) antibody (dilution WB 1:1000) (9661, Cell Signaling Technology, Danvers, MA, USA), rabbit anti-caspase-3 (dilution WB 1:1000) (8G10, Cell Signaling Technology, Apoptosis and DNA damage H2AX (S139) and cleaved PARP and antiGAPDH western blot cocktail antibody (dilution WB 1:1000) (ab131385, Abcam Australia, Pty, Ltd) rabbit anti- $\gamma \mathrm{H} 2 \mathrm{AX}$ (P139) (dilution WB 1:1000, IF/PLA 1:200) (ab2893, Abcam Australia, Pty, Ltd), rabbit anti- $\gamma \mathrm{H} 2 \mathrm{AX}$ antibody (dilution WB 1:1000) (ab11175, Abcam Australia), mouse anti-GFP (dilution WB 1:3000, IF/PLA 1:500) (11814460001, Roche), mouse anti-Tubulin (dilution WB 1:3000) (clone DM1A, T9026, Sigma-Aldrich), mouse anti-Cherry (dilution WB 1:2000) (5411-100, BioVision), and mouse anti-GAPDH (WB 1:2000) (AM4300, Thermo Fisher Scientific).

DNA constructs. Murine Cavin- 1 constructs were described previously ${ }^{67}$. Murine Cavin-2 (Fantom 2 clone 9530015P22) and Cavin-3 (amplified from NIH-3T3 fibroblast cDNA) were cloned in either pEGFP vectors or mCherry vectors as previously described ${ }^{3}$. PP1alpha-GFP construct was kindly provided by the Trinkle-Mulcahy Laboratory, Canada.

Plasmid preparation and cell-free expression. Proteins were tagged with enhanced GFP (GFP), mCherry and cMyc (myc) tags, and cloned into cell-freeexpression Gateway destination vectors: N-terminal GFP tagged (pCellFree_G03), N-terminal Cherry-cMyc (pCellFree_G07), and C-terminal Cherry-cMyc tagged (pCellFree_G08). Human RBPJ (BC020780) and MEF2C (BC026341) open reading frames (ORFs) were sourced from the Human ORFeome collection, version 1.1 and 5.1, and the Human Orfeome collaboration OCAA collection (Open Biosystems), as previously described ${ }^{16}$ and cloned at the ARVEC facility, UQ Diamantina Institute. Translation competent Leishmania tarentolae extract (LTE) were prepared as previously described ${ }^{16-18,68}$. Protein pairs were co-expressed by adding 30 $\mathrm{nM}$ of GFP template plasmid and $60 \mathrm{nM}$ of Cherry template plasmid to LTE and incubating for $3 \mathrm{~h}$ at $27^{\circ} \mathrm{C}$.
Cell culture. MCF-7 cells, a human adenocarcinoma cell line (ATCC HTB-22), were subjected to STR profiling (QIMR Berhofer Medical Research Institute), A431 cells (ATCC CRL-1555), a human skin/epidermis cell line and MDA-MB231 cells (ATCC HTB-26), were cultured in DMEM supplemented with $10 \%$ (vol/vol) FBS, 100 units $/ \mathrm{ml}$ penicillin and $100 \mu \mathrm{g} / \mathrm{ml}$ streptomycin. All cell lines were subjected to routine mycoplasma testing. It should be noted that there is some discrepancy in the literature as to whether MCF-7 cells express CAV1 with some studies showing clear CAV1 mRNA and protein expression ${ }^{69,70}$ whereas other studies show no CAV1 mRNA or protein expression ${ }^{71,72}$. Therefore, MCF-7 cells should be tested on a per laboratory basis for expression of CAV1 and the cavin proteins, respectively.

Immunofluorescence. In brief, MCF-7, MDA-MB231, or A431 cells seeded onto glass coverslips at $70 \%$ confluence were washed once in PBS and then fixed in $4 \%$ (vol/vol) PFA in PBS for 20 min at RT. Coverslips were washed three times in excess PBS and were permeabilized in $0.1 \%$ (vol/vol) Triton X-100 in PBS for $7 \mathrm{~min}$ and blocked in $1 \%$ (vol/vol) BSA (Sigma-Aldrich) in PBS for 30 min at RT. The primary antibodies were diluted in $1 \%(\mathrm{vol} / \mathrm{vol}) \mathrm{BSA}$ in PBS and incubated for $1 \mathrm{~h}$ RT. Secondary antibodies (Molecular Probes) were diluted in $1 \%$ (vol/vol) BSA in PBS and incubated for $1 \mathrm{~h} \mathrm{RT}$. Washes were performed in PBS. Coverslips were rinsed in distilled water and mounted in Mowiol (Mowiol 488, Hoechst AG) in 0.2 $\mathrm{M}$ Tris-HCL, $\mathrm{pH}$ 8.5. The images were taken on a laser-scanning microscope (LSM 510 META, Carl Zeiss, Inc) using a $\times 63$ oil lens, NA 1.4. Adjustments of brightness and contrast were applied using Image J software (NIH).

SDS-PAGE and western blot analysis. For SDS-PAGE, cells were harvested, rinsed in PBS and were lysed in lysis buffer containing $50 \mathrm{mM}$ Tris pH 7.5, $150 \mathrm{mM}$ $\mathrm{NaCl}, 5 \mathrm{mM}$ EDTA pH 8.0,1\% Triton X-100 with protease and phosphatase inhibitors. Lysates were collected by scraping and cleared by centrifugation at $4{ }^{\circ} \mathrm{C}$. The protein content of all extracts was determined using a BCA protein assay kit (Thermo Fisher Scientific, Victoria, Australia) using bovine serum albumin (BSA) as the standard. Thirty micrograms of cellular protein were resolved by $10 \%$ SDSPAGE and were transferred to PVDF membranes (Millipore). Bound IgG was visualized with horseradish peroxidase-conjugated secondary antibodies and the Super Signal West Dura ECL detection reagent (Life Technologies) and was imaged using the ChemiDoc Imaging System (Bio-rad, Gladesville, New South Wales, Australia). Uncropped and unprocessed scans of the all blots presented in the main figures are available as a Supplementary Fig. 11 in the Supplementary Information.

Proximity ligation assay (PLA). Detection of an interaction between proteins was assessed using the Duolink II Detection Kit (Sigma-Aldrich) according to the manufacturer specifications. The signal was visualized as a distinct fluorescent spot and was captured on an Olympus BX-51 upright Fluorescence Microscope using a $\times 60 / 1.35$ oil lens. The number of PLA signals in a cell was quantified in Image J using a Maximum Entropy Threshold and Particle Analysis where 50 cells in each treatment group were analyzed for at least three independent experiments. RGB images were converted to black/white images with the Invert LUT from Image J.

Stress experiments. A431 or MDA-MB231 cells were plated on coverslips at $70 \%$ confluency. Cells were either left untreated or were treated with $70 \%$ hypo-osmotic media $\left(70 \% \mathrm{H}_{2} \mathrm{O}\right.$ in DMEM) for $10 \mathrm{~min}$, or UV treatment for $2 \mathrm{~min}$ without media with a UV germicidal light source and allowed to recover in complete cell culture medium. All cells were fixed and processed using the Proximity Ligation assay as described.

RNA interference. Human Cavin3 Stealth siRNAs (set of 3-HSS174185, 150811, 150809), Human PP1a Stealth siRNAs (set of 3-HSS101089, 186096, 186097), and Stealth RNAi Negative Control Kit were purchased from Life Technologies Australia Pty Ltd. RNA oligonucleotides to Cavin3 or PP1a were transfected into cells at $24 \mathrm{~h}$ and $48 \mathrm{~h}$ after plating using Lipofectamine 3000 reagent (Invitrogen) with a ratio of $6 \mu$ l Lipofectamine to 150 pmol siRNA. Cells were split and harvested after 72-96 h for further analysis.

Apoptosis assay. Equal numbers of sub-confluent of control or Cavin3 or PP1a knockdown A431 cells were plated in 12-well dishes. Twenty-four hours later, cells were subject to UV C exposure for $2 \mathrm{~min}$ without media. Complete medium lacking phenol red was added to the cells that were left for an additional $4 \mathrm{~h}$ at $37^{\circ}$ $\mathrm{C}$ to recover. $\mathrm{LDH}$ release assay was measured in triplicate samples from $50 \mu \mathrm{L}$ of conditioned media from each 12 well of cells using the Cytotoxicity Detection Kit (LDH) from Roche Diagnostics according to the manufacturer's instructions. Post nuclear supernatant from UV exposure cells were also prepared and were subjected to western blot analysis with antibodies to GFP (Roche), cleaved PARP (ABCAM), cleaved-caspase-3 (Cell Signaling), caspase-3 (Cell Signaling), Apoptosis and DNA damage H2AX (S139) and cleaved PARP and anti-GAPDH western blot cocktail antibody (Abcam), $\gamma \mathrm{H} 2 \mathrm{AX}$ (P139) (Abcam), mouse anti-GFP (Roche, Basel, Switzerland) and Tubulin (Abcam). 
Single-molecule spectroscopy. Single-molecule spectroscopy was performed based on Leishmania cell-free lysates were prepared according to ${ }^{16-18,68}$. Where indicated MCF-7 cells were transiently cotransfected with GFP-PP1 $\alpha$ and mCherry alone as the control, Cherry-Cavin1 or Cherry-Cavin3 constructs. A PNS fraction from the MCF-7 cells was prepared in PBS with protease and phosphatase inhibitors. Single-molecule coincidence measurements were performed using pairs of tagged proteins to ascertain their interaction. One protein of the pair was tagged with GFP, and the other with mCherry, and both were diluted to single-molecule concentrations $(\sim 1 \mathrm{nM})$. Two lasers, with wavelengths of $488 \mathrm{~nm}$ and $561 \mathrm{~nm}$ (to excite GFP and mCherry, respectively), were focused to a confocal volume using a $40 \times / 1.2$ NA water immersion objective. The fluorescence signal from the fluorophores was collected and separated into two channels with a $565 \mathrm{~nm}$ dichroic. The resulting GFP and mCherry signals were measured after passing through a 525/20 $\mathrm{nm}$ band pass and $580 \mathrm{~nm}$ long pass filter, respectively. The signal from both channels was recorded simultaneously with a time resolution of $1 \mathrm{~ms}$, and the threshold for positive events was set at 50 photons $/ \mathrm{ms}$. The coincidence ratio (C) for each event was calculated as $\mathrm{C}=\mathrm{mCherry} /(\mathrm{GFP}+\mathrm{mCherry})$, after subtracting a $6 \%$ leakage of the GFP signal into the mCherry channel. Coincident events corresponded to $\sim 0.25<\mathrm{C}<0.75$. After normalizing for the total number of events (>1000 in all cases), a histogram of the $\mathrm{C}$ values for the protein pair was fitted with three Gaussians, corresponding to signals from solely GFP (green), coincidence (yellow), and solely mCherry (red).

GFP Trap. For each immunoprecipitation reaction, $3 \times 10 \mathrm{~cm}$ dishes of MCF-7 or A431 cells expressing a GFP-tagged protein were extensively washed in ice-cold PBS three times followed by addition of RIPA buffer containing protease and phosphatase inhibitors (Roche). Tubes were placed on ice for 20 min with extensively pipetting every $10 \mathrm{~min}$ cell lysates were centrifuged at $20,000 \times g$ for $10 \mathrm{~min}$ at $4{ }^{\circ} \mathrm{C}$. Lysate-supernatants were transferred to a pre-cooled tube and the pellet was discarded. GFP Trap beads were equilibrated in $0.5 \mathrm{ml}$ of ice-cold RIPA buffer and were spun down at $2.500 \times g$ for $2 \mathrm{~min}$ at $4^{\circ} \mathrm{C}$. Beads were washed two more times with $500 \mu \mathrm{l}$ RIPA buffer. In total, 1-2 mg of lysate-supernatant was added to equilibrated GFP Trap beads and were incubated for $1 \mathrm{~h}, 4^{\circ} \mathrm{C}$ with constant mixing. Tubes were spun at $2.500 \times g$ for $2 \mathrm{~min}$ at $4{ }^{\circ} \mathrm{C}$. GFP Trap beads were washed three times with $500 \mu \mathrm{l}$ ice-cold RIPA buffer. One hundred microliters of $2 \times$ SDS sample buffer was then added to the GFP Trap beads and were boiled for $10 \mathrm{~min}$ at $95^{\circ} \mathrm{C}$. The beads were collected by centrifugation at $2.500 \times g$ for $2 \mathrm{~min}$ and SDS-PAGE was performed with the supernatant.

Biotin ligase transfection and purification. MCF- 7 cells at $80 \%$ confluency were transfected with BirA-IRES-GFP (control) or BirA-IRES-Cavin3 using Lipofectamine 3000 according to the manufacturer's instructions. After $3 \mathrm{~h}$, the cell culture medium was replaced with $2 \mathrm{ml}$ of fresh medium containing $10 \%$ FBS serum and $50 \mu \mathrm{M}$ biotin. Cells were further incubated for $18 \mathrm{~h}$ at $37^{\circ} \mathrm{C}$. Cells were washed three times with ice-cold PBS and were lysed in RIPA buffer $(50 \mathrm{mM}$ Tris- $\mathrm{HCl} \mathrm{pH}$ 7.5, $150 \mathrm{mM} \mathrm{NaCl}, 0.1 \%$ SDS, $1 \%$ Triton X-100 and $5 \mathrm{mM}$ EDTA) containing phosphatase and protease inhibitors (Roche). Cell extracts were lysed with a 25gauge needle and syringe, 10-20 times and were incubated on ice for $20 \mathrm{~min}$. Samples were spun at $14,000 \times g$ for $10 \mathrm{~min}$ at $4^{\circ} \mathrm{C}$ and the supernatant was removed. High affinity strepavidin agarose beads (Thermo Scientific) with washed three times with RIPA buffer and was added to $2 \mathrm{mg}$ of total cell extract that was left to rotate at $4{ }^{\circ} \mathrm{C}$ overnight. The agarose beads were pelleted at $2500 \times g$ and washed three times in RIPA buffer. Eighty microliters of $2 \times$ SDS-PAGE sample buffer containing DTT was added to the beads and boiled $5 \mathrm{~min}$ at $95^{\circ} \mathrm{C}$. All samples were pelleted at $2500 \times g$ for 5 min at RT before loading on an SDS-PAGE gel. Western blot membranes were blocked with 5\% BSA in TBST for at least $1 \mathrm{~h}$ and were extensively wash (four times) with TBST 10 min prior to detection with Clarity Western ECL substrates (Bio-Rad Laboratories, Hercules, California, USA).

ALPHAScreen. ALPHAScreen was performed as previously described ${ }^{16-18}$, using the cMyc detection kit and Proxiplate-384 Plus plates (PerkinElmer). The plates were incubated for $45 \mathrm{~min}$ at room temperature, followed by the addition of streptavidin-coated donor beads and incubation in the dark for $45 \mathrm{~min}$ at room temperature. The ALPHAScreen signal was measured on an Enivision Plate Reader (PerkinElmer) using manufacturer's recommended settings. Data from three independent experiments was analyzed in GraphPad Prism version 6.0. The luminescence intensities plotted are averages over three independent expressions/ experiments where for each experiment, the signal intensity from a negative control, GFP alone in solution was substracted. An average of all the normalized data for both configuration of each protein pair (GFP-protein A/protein B-Cherry or GFP protein B/protein A-Cherry) was calculated to provide the binding index where values above 2000 were considered background. From previous experiments ${ }^{16-18}$, a threshold of above 2000 (background) selected positive interactions and was therefore employed in these studies.

AlphaLISA assay. GFP-tagged HR1, HR2 and HR1+HR2, Cavin3 and Cavin1, and Cherry-tagged PP1 $\alpha$ were co-expressed in an LTE system ${ }^{73}$. Following their expression, the protein mixture was diluted 100 times with buffer A $(25 \mathrm{mM}$ HEPES, $50 \mathrm{mM} \mathrm{NaCl}, 0.1 \% \mathrm{BSA}$ and $0.01 \%$ Nonidet P-40). The AlphaLISA assay was carried out in an Optiplate-384 Plus plate, using anti-GFP AlphaLISA acceptor and streptavidin donor beads. Alpha beads were prepared according to the protocol provided by PerkinElmer. The alpha acceptor and donor beads stocks were diluted to $100 \mu \mathrm{g} / \mathrm{mL}$ in $1 \mathrm{X}$ AlphaLISA Universal assay buffer. The biotinylated mCherry nanobody $(100 \mathrm{nM})$ was added into microplate wells followed by addition of $15 \mu \mathrm{L}$ protein mixture (PP1 $\alpha$-Cherry and GFP-Cavin3) and (PP1 1 -Cherry and GFPFKBP) as a negative control. All samples were prepared in triplicate. The acceptor beads $(5 \mu \mathrm{L})$ were added to each well and the mixture was incubated for $1 \mathrm{~h}$ at room temperature. Finally, $5 \mu \mathrm{L}$ of donor beads were added to the samples under subdued light, mixed gently and incubated $30 \mathrm{~min}$ at RT. The AlphaLISA signal was detected with a Tecan microplate reader using the following setting: Filter: AlphaLISA, Excitation time: $180 \mathrm{~ms}$, Integration time: $300 \mathrm{~ms}$.

Mass spectrometry of GFP Trap pulldowns. Pulldowns were eluted in SDSPAGE sample buffer and separated on 10\% SDS-PAGE gels to $2 \mathrm{~mm}$ only. Protein visualization, excision of bands and in-gel trypsin digest were performed using a semi-automated method as described in ref. ${ }^{74}$. Peptides were analyzed using either Agilent nano-LC QTOF with Spectrum Mill for database searching as previous described $^{75}$, or using the following method. Thermo Scientific Q Exactive Plus Orbitrap Mass Spectrometer coupled with Easy-nLC 1000 and EASY-spray ion source was used to analyze the digested peptides. Samples were loaded onto an EASY-Spray PepMap RSLC C18 $2 \mu \mathrm{m}$ column $(25 \mathrm{~cm} \times 75 \mu \mathrm{m}$ ID), with a nanoviper acclaim $\mathrm{C} 18$ guard $(75 \mathrm{~m} \times 2 \mathrm{~cm})$. A 62 min method was run using a combination of Buffer A (0.1\% Formic acid) and Buffer B (0.1\% Formic acid: Acetonitrile). A two-step gradient was run comprising a 10 min gradient from 3 to $10 \%$ Buffer B and a 30 min gradient from 10 to $32 \%$ Buffer B. Flow rate was at $3 \mathrm{~L} /$ min. The mass spectrometer was programmed to acquire a full MS resolution of 70,000 with an ACG target of $3 e 6$ with a maximum injection time of $100 \mathrm{~ms}$. The MS scan range was from 350 to $1400 \mathrm{~m} / z$. MS/MS was set to acquire a resolution of 35,000 with an ACG target of 5e5 and maximum injection time of $110 \mathrm{~ms}$. The loop count was set to 20 with a dynamic exclusion after $10 \mathrm{~s}$.

Raw data were processed with Proteome Discoverer (Thermo, 2.0.0.802). Selected modifications included fixed carbamidomethylation of cysteine and variable oxidized methionine. Results were searched against the Human SwissProt database (v2015-09-16) using the Sequest HT node. Trypsin was selected for enzyme digest, with three maxima missed cleavages allowed. The precursor mass tolerance was set at $+/-10 \mathrm{ppm}$ and fragment mass tolerance was $0.08 \mathrm{Da}$. False discovery rate was set to 0.05 using the percolator node. Search parameters were defined as a rapid search using trypsin digestion enzyme, iodoacetamide cysteine alkylation and all entries in the database. Proteins were considered identified if there were two or above peptides identified with a $99 \%$ confidence and a $1 \%$ global false discovery rate (FDR). Network representation of selected biological processes and pathways was performed using Ingenuity Pathway analysis (QIAGEN Bioinformatics) content version 18841524 . The mass spectrometry proteomics data have been deposited to the ProteomeXchange Consortium via the PRIDE partner repository with the dataset identifier PXD014081.

Nano HPLC, mass spectrometry, and protein identification for BiolD. For BioID/MS, the human cell protein, trypsin digested, extracts were analyzed by nanHPLC/MS MS/MS on a Shimadzu Prominance Nano HPLC (Japan) coupled to a Triple Tof 5600 mass spectrometer (ABSCIEX, Canada) equipped with a nano electrospray ion source. Sixteen microliters of each extract was injected onto a 50 $\mathrm{mm} \times 300 \mu \mathrm{m}$ C18trap column (Agilent Technologies, Australia) at $30 \mu \mathrm{l} / \mathrm{min}$. The samples were de-salted on the trap column for $5 \mathrm{~min}$ using $0.1 \%$ formic acid (aq) at $30 \mu \mathrm{L} / \mathrm{min}$. The trap column was then placed in-line with the analytical nano HPLC column, a $150 \mathrm{~mm} \times 100 \mu \mathrm{m}$ 300SBC18, $3.5 \mu \mathrm{m}$ (Agilent Technologies, Australia) for mass spectrometry analysis. Linear gradients of $1-40 \%$ solvent B over $50 \mathrm{~min}$ at 300 $\mathrm{nL} / \mathrm{min}$ flow rate, followed by a steeper gradient from 40 to $80 \%$ solvent $\mathrm{B}$ in $5 \mathrm{~min}$ were used for peptide elution. Solvent B was held at $80 \%$ for 6 min for washing the column and returned to $1 \%$ solvent B for equilibration prior to the next sample injection. Solvent A consisted of $0.1 \%$ formic acid (aq) and solvent B contained $90 / 10$ acetonitrile $/ 0.1 \%$ formic acid (aq). The ionspray voltage was set to $2400 \mathrm{~V}$, declustering potential (DP) $100 \mathrm{~V}$, curtain gas flow 25, nebulizer gas 1 (GS1) 12 and interface heater at $150{ }^{\circ} \mathrm{C}$. The mass spectrometer acquired $500 \mathrm{~ms}$ full scan TOF-MS data followed by 20 by $50 \mathrm{~ms}$ full scan product ion data in an Information Dependant Acquisition, IDA, mode. Full scan TOFMS data were acquired over the mass range $300-1400$ and for product ion $\mathrm{ms} / \mathrm{ms} 80-1400$. Ions observed in the TOF-MS scan exceeding a threshold of 120 counts and a charge state of +2 to +5 were set to trigger the acquisition of product ion, $\mathrm{ms} / \mathrm{ms}$ spectra of the resultant 20 most intense ions. The data were acquired and processed using Analyst TF 1.6.1 software (ABSCIEX, Canada). Proteins were identified by database searching using ProteinPilot v4.5 (ABSCIEX, Canada) against the UniProt Sprot 20130205 Human Protein database ( $\sim 40,532$ entries searched, FDR of $1 \%)$. The mass spectrometry proteomics data have been deposited to the ProteomeXchange Consortium via the PRIDE partner repository with the dataset identifier PXD014094.

Electron microscopy. For electron microscopy, A431 cells were either left untreated or were treated with UV for $2 \mathrm{~min}$ as described and then further incubated for 30 min before fixation for epon embedding or were treated with $70 \%$ 
hypo-osmotic medium (70\% water in DMEM, $10 \mathrm{~min}$ ). Sections were cut perpendicular to the culture substratum. Processing and quantitation of the density of caveolae was performed on over 30 images for each condition captured at a primary magnification of $25 \mathrm{kx}$ on a Jeol 1010 or Jeol 1011. Three sets of images from three independent experiments were analyzed for the presence of caveolae on the apical surface of the cell and normalized to the length of surface sampled (over 150 $\mu \mathrm{m}$ for each set of images). Imaging and quantification for all EM studies were performed in a blinded fashion.

Phosphatase activity assay. MCF-7 cells transfected with mScarlet-PP1 $\alpha$ or/and pCB6-Cavin3 DNA were lysed in lysis buffer $(20 \mathrm{mM}$ Tris- $\mathrm{HCl}, \mathrm{pH} 7.4,132 \mathrm{mM}$ $\mathrm{NaCl}, 10 \%$ Glycerol, $1 \%$ Triton X-100, and a protease inhibitor cocktail tablet from Roche). Lysates containing $500 \mu \mathrm{g}$ protein (made up to $500 \mu \mathrm{L}$ by lysis buffer) were precleared with protein A-coupled sepharose beads $(20 \mu \mathrm{L})$. After centrifuging at $2500 \times g$ for $1 \mathrm{~min}$, supernatants were collected and immunoprecipitated with antiPP1a antibody (ab137512, Abcam) overnight at $4{ }^{\circ} \mathrm{C}$. Protein A $(20 \mu \mathrm{L})$ was added for another $3 \mathrm{~h}$ incubation. The beads were washed three times with lysis buffer and then resuspended in $50 \mu \mathrm{L}$ of reaction buffer $(50 \mathrm{mM}$ Tris- $\mathrm{HCl}$ at $\mathrm{pH} 7.0$ containing 0.1 $\mathrm{mM} \mathrm{CaCl}, 125 \mu \mathrm{g} / \mathrm{mL}$ BSA and $0.05 \%$ Tween 20) provided by the RediPlate 96 EnzChek serine/threonine phosphatase activity assay kit (R33700, Thermo Fisher). Reaction buffer containing immunoprecipitates was then added into the wells incorporated with $50 \mu \mathrm{M}$ phosphatase substrate 6,8-difluoro-4-methylumbelliferyl phosphate for a $30 \mathrm{~min}$ incubation at $37^{\circ} \mathrm{C}$ in the dark. Fluorescence was then measured at an excitation wavelength of $355 \mathrm{~nm}$ and an emission wavelength of 460 $\mathrm{nm}$ using a TECAN microplate reader. Relative phosphatase activity was calculated as a percentage of the control.

Gene expression analysis in MCF-7 cells. Human Cavin 1,2 and 3, and Caveolin1 gene expression was analyzed using the Taqman Gene Expression assay (Life Technologies Australia, Applied Biosystems Division). RT PCR primers used were Hs00396859_m1 Cavin1, Hs00190538_m1 Cavin2, Hs04194683_s1 Cavin3, Hs00971716_ml Cav1, and Hs00427620_ml TBP as the endogenous control. Total RNA was extracted from cells using the TRI reagent (Sigma-Aldrich) according to the manufacturer's protocol. RNA was further purified using a mini-Uneasy kit (QIAGEN) according to manufacturer's instructions and quantified using a NanoDrop ND-1000 spectrophotometer. cDNA was synthesized from $1 \mu \mathrm{g}$ of total RNA for cell culture and using Superscript III primed by oligo dT (Geneworks), according to the manufacturer's instructions (Invitrogen). Target cDNA levels were compared with qRT-PCR in $25 \mu \mathrm{l}$ reactions containing Taqman PCR master mix (Roche Molecular Systems) $1 \times$ Assay-on-Demand Taqman primers and the equivalent of $0.3 \mu \mathrm{L}$ cDNA. Using an ABI Prism 7500 (Applied Biosystems) sequence detection system, PCR was conducted over 45 cycles of $95^{\circ} \mathrm{C}$ for $15 \mathrm{~s}$ and $60^{\circ} \mathrm{C}$ for $1 \mathrm{~min}$, preceded by an initial $95^{\circ} \mathrm{C}$ for $10 \mathrm{~min}$. Expression levels were normalized to HPRT1 as determined from the ratio of delta CT values. All results are expressed as mean \pm SEM from five independent replicates. Statistical analyses were performed using GraphPad Prism Version6a (California, USA). All qRT-PCR data were analyzed using a one-way ANOVA with a Tukey's multiple correction test.

Statistical analyses. Statistical analyses were conducted using Microsoft Excel and Prism (GraphPad). Error bars represent either standard deviation (SD) or standard error of the mean (SEM) for at least three independent experiments, as indicated in the figure legends. Statistical significance was determined either by two-tailed Student's $t$ test or by one-way ANOVA, as indicated in the figure legends. Significance was calculated where ${ }^{*} p<0.05,{ }^{* *} p<0.01,{ }^{* * *} p<0.001$, and ${ }^{* * * *} p<0.0001$.

Reporting summary. Further information on research design is available in the Nature Research Reporting Summary linked to this article.

\section{Data availability}

The source data underlying Supplementary Figures 2 and 4, and Supplementary Data 1 (mass spectrometry data from BioID and GFP-Trap experiments) are provided as a source data file titled "NCOMMS-18-13078A_Source_Data" in a single excel file. All reagents and further experimental data are available from the corresponding author upon reasonable request. Proteomics data for BioID and GFP-Trap experiments that supports the findings of this study have been deposited to the ProteomeXchange Consortium via the PRIDE repository separately with the dataset identifier PXD014094 (BioID) and PXD014081 (GFP-Trap).

Received: 29 April 2018 Accepted: 14 June 2019

Published online: 22 July 2019

\section{References}

1. Parton, R. G. \& del Pozo, M. A. Caveolae as plasma membrane sensors, protectors and organizers. Nat. Rev. Mol. Cell Biol. 14, 98-112 (2013).
2. Ariotti, N. \& Parton, R. G. SnapShot: caveolae, caveolins, and cavins. Cell 154, 704-704 e701 (2013).

3. Bastiani, M. et al. MURC/Cavin-4 and cavin family members form tissuespecific caveolar complexes. J. Cell Biol. 185, 1259-1273 (2009).

4. Hansen, C. G., Bright, N. A., Howard, G. \& Nichols, B. J. SDPR induces membrane curvature and functions in the formation of caveolae. Nat. Cell Biol. 11, 807-814 (2009).

5. Kovtun, O., Tillu, V. A., Ariotti, N., Parton, R. G. \& Collins, B. M. Cavin family proteins and the assembly of caveolae. J. Cell Sci. 128, 1269-1278 (2015).

6. Lo, H. P. et al. The caveolin-cavin system plays a conserved and critical role in mechanoprotection of skeletal muscle. J. Cell Biol. 210, 833-849 (2015).

7. McMahon, K. A. et al. SRBC/cavin-3 is a caveolin adapter protein that regulates caveolae function. EMBO J. 28, 1001-1015 (2009).

8. Gambin, Y. et al. Single-molecule analysis reveals self assembly and nanoscale segregation of two distinct cavin subcomplexes on caveolae. Elife 3, e01434 (2013).

9. Sinha, B. et al. Cells respond to mechanical stress by rapid disassembly of caveolae. Cell 144, 402-413 (2011).

10. Jansa, P., Mason, S. W., Hoffmann-Rohrer, U. \& Grummt, I. Cloning and functional characterization of PTRF, a novel protein which induces dissociation of paused ternary transcription complexes. EMBO J. 17, 2855-2864 (1998)

11. Burgener, R., Wolf, M., Ganz, T. \& Baggiolini, M. Purification and characterization of a major phosphatidylserine-binding phosphoprotein from human platelets. Biochem. J. 269, 729-734 (1990).

12. Mineo, C., Ying, Y. S., Chapline, C., Jaken, S. \& Anderson, R. G. Targeting of protein kinase Calpha to caveolae. J. Cell Biol. 141, 601-610 (1998).

13. Hernandez, V. J. et al. Cavin-3 dictates the balance between ERK and Akt signaling. Elife 2, e00905 (2013).

14. Agrawal, P., Yu, K., Salomon, A. R. \& Sedivy, J. M. Proteomic profiling of Myc-associated proteins. Cell Cycle 9, 4908-4921 (2010).

15. Schneider, K. et al. CAVIN-3 regulates circadian period length and PER:CRY protein abundance and interactions. EMBO Rep. 13, 1138-1144 (2012).

16. Sierecki, E. et al. A cell-free approach to accelerate the study of protein-protein interactions in vitro. Interface Focus 3, 20130018 (2013).

17. Sierecki, E. et al. Rapid mapping of interactions between Human SNX-BAR proteins measured in vitro by AlphaScreen and single-molecule spectroscopy. Mol. Cell Proteom. 13, 2233-2245 (2014).

18. Moustaqil, M. et al. Homodimerization regulates an endothelial specific signature of the SOX18 transcription factor. Nucleic Acids Res. 46, 11381-11395 (2018).

19. Roux, K. J., Kim, D. I., Raida, M. \& Burke, B. A promiscuous biotin ligase fusion protein identifies proximal and interacting proteins in mammalian cells. J. Cell Biol. 196, 801-810 (2012).

20. Ullman, E. F. et al. Luminescent oxygen channeling immunoassay: measurement of particle binding kinetics by chemiluminescence. Proc. Natl Acad. Sci. USA 91, 5426-5430 (1994).

21. Pelkmans, L. \& Zerial, M. Kinase-regulated quantal assemblies and kiss-andrun recycling of caveolae. Nature 436, 128-133 (2005).

22. Hirano, A. et al. USP7 and TDP-43: pleiotropic regulation of cryptochrome protein stability paces the oscillation of the mammalian circadian clock. PloS ONE 11, e0154263 (2016).

23. Liu, L., Hansen, C. G., Honeyman, B. J., Nichols, B. J. \& Pilch, P. F. Cavin-3 knockout mice show that cavin-3 is not essential for caveolae formation, for maintenance of body composition, or for glucose tolerance. PloS ONE 9, e102935 (2014)

24. Mureev, S., Kovtun, O., Nguyen, U. T. \& Alexandrov, K. Species-independent translational leaders facilitate cell-free expression. Nat. Biotechnol. 27, 747-752 (2009).

25. Gagoski, D. et al. Performance benchmarking of four cell-free protein expression systems. Biotechnol. Bioeng. 113, 292-300 (2016).

26. Tillu, V. A. et al. A variable undecad repeat domain in cavin1 regulates caveola formation and stability. EMBO Rep. 19, e45775(2018).

27. Ahmed, N. et al. Modulation of PP2A activity by Jacalin: is it through caveolae and ER chaperones? Glycoconj. J. 27, 723-734 (2010).

28. Lee, M. Y., Lee, S. H., Park, J. H. \& Han, H. J. Interaction of galectin-1 with caveolae induces mouse embryonic stem cell proliferation through the Src, ERas, Akt and mTOR signaling pathways. Cell Mol. Life Sci. 66, 1467-1478 (2009).

29. Chan, W. H., Wu, C. C. \& Yu, J. S. Curcumin inhibits UV irradiation-induced oxidative stress and apoptotic biochemical changes in human epidermoid carcinoma A431 cells. J. Cell. Biochem. 90, 327-338 (2003).

30. Lin, J. R., Qin, H. H., Wu, W. Y., He, S. J. \& Xu, J. H. Vitamin C protects against UV irradiation-induced apoptosis through reactivating silenced tumor suppressor genes p21 and p16 in a Tet-dependent DNA demethylation 
manner in human skin cancer cells. Cancer Biother. Radio. 29, 257-264 (2014).

31. Lee, J. H. et al. Frequent epigenetic inactivation of hSRBC in gastric cancer and its implication in attenuated p53 response to stresses. Int. J. Cancer 122, 1573-1584 (2008).

32. Lee, J. H. et al. Epigenetic alteration of PRKCDBP in colorectal cancers and its implication in tumor cell resistance to TNFalpha-induced apoptosis. Clin. Cancer Res. 17, 7551-7562 (2011).

33. Ghosal, G. \& Chen, J. DNA damage tolerance: a double-edged sword guarding the genome. Transl. Cancer Res. 2, 107-129 (2013).

34. Roos, W. P., Thomas, A. D. \& Kaina, B. DNA damage and the balance between survival and death in cancer biology. Nat. Rev. Cancer 16, 20-33 (2016).

35. de Feraudy, S., Revet, I., Bezrookove, V., Feeney, L. \& Cleaver, J. E. A minority of foci or pan-nuclear apoptotic staining of gammaH2AX in the S phase after UV damage contain DNA double-strand breaks. Proc. Natl Acad. Sci. USA 107, 6870-6875 (2010).

36. Sharma, A., Singh, K. \& Almasan, A. Histone H2AX phosphorylation: a marker for DNA damage. Methods Mol. Biol. 920, 613-626 (2012).

37. Shimada, M. \& Nakanishi, M. Response to DNA damage: why do we need to focus on protein phosphatases? Front Oncol. 3, 8 (2013).

38. Peti, W., Nairn, A. C. \& Page, R. Structural basis for protein phosphatase 1 regulation and specificity. FEBS J. 280, 596-611 (2013).

39. Watanabe, T. et al. Protein phosphatase 1 regulation by inhibitors and targeting subunits. Proc. Natl Acad. Sci. USA 98, 3080-3085 (2001)

40. Sydnes, M. O. \& Isobe, M. Tautomycin's interactions with protein phosphatase 1. Chem. Asian J. 5, 410-420 (2010).

41. Rees, J. S., Li, X. W., Perrett, S., Lilley, K. S. \& Jackson, A. P. Protein Neighbors and Proximity Proteomics. Mol. Cell Proteom. 14, 2848-2856 (2015).

42. Liu, L. \& Pilch, P. F. PTRF/Cavin-1 promotes efficient ribosomal RNA transcription in response to metabolic challenges. Elife 5, e17508 (2016).

43. Tillu, V. A., Kovtun, O., McMahon, K. A., Collins, B. M. \& Parton, R. G. A phosphoinositide-binding cluster in cavin1 acts as a molecular sensor for cavin1 degradation. Mol. Biol. Cell. 26, 3561-3569 (2015).

44. Bai, L. et al. Regulation of cellular senescence by the essential caveolar component PTRF/Cavin-1. Cell Res. 21, 1088-1101 (2011).

45. Gupta, R., Toufaily, C. \& Annabi, B. Caveolin and cavin family members: dual roles in cancer. Biochimie 107(Pt B), 188-202 (2014)

46. Liu, L. et al. Cavin-1 is essential for the tumor-promoting effect of caveolin-1 and enhances its prognostic potency in pancreatic cancer. Oncogene 33, 2728-2736 (2014).

47. Wang, Z. et al. Caveolin-1, a stress-related oncotarget, in drug resistance. Oncotarget 6, 37135-37150 (2015).

48. Yi, J. S. et al. PTRF/cavin-1 is essential for multidrug resistance in cancer cells. J. Proteome Res. 12, 605-614 (2013).

49. Baure, J. et al. Histone H2AX phosphorylation in response to changes in chromatin structure induced by altered osmolarity. Mutagenesis 24, 161-167 (2008).

50. Cohen, P. T. Protein phosphatase 1-targeted in many directions. J. Cell Sci. 115, 241-256 (2002)

51. Ceulemans, H. \& Bollen, M. Functional diversity of protein phosphatase1, a cellular economizer and reset button. Physiol. Rev. 84, 1-39 (2004).

52. Korrodi-Gregorio, L., Esteves, S. L. \& Fardilha, M. Protein phosphatase 1 catalytic isoforms: specificity toward interacting proteins. Transl. Res. 164, 366-391 (2014).

53. Hendrickx, A. et al. Docking motif-guided mapping of the interactome of protein phosphatase-1. Chem. Biol. 16, 365-371 (2009).

54. Flores-Delgado, G., Liu, C. W., Sposto, R. \& Berndt, N. A limited screen for protein interactions reveals new roles for protein phosphatase 1 in cell cycle control and apoptosis. J. proteome Res. 6, 1165-1175 (2007).

55. Brichese, L., Cazettes, G. \& Valette, A. JNK is associated with Bcl-2 and PP1 in mitochondria: paclitaxel induces its activation and its association with the phosphorylated form of Bcl-2. Cell Cycle 3, 1312-1319 (2004).

56. Chatfield, K. \& Eastman, A. Inhibitors of protein phosphatases 1 and $2 \mathrm{~A}$ differentially prevent intrinsic and extrinsic apoptosis pathways. Biochem. Biophys. Res. Commun. 323, 1313-1320 (2004).

57. Garcia, A. et al. Serine/threonine protein phosphatases PP1 and PP2A are key players in apoptosis. Biochimie 85, 721-726 (2003).

58. Caren, H. et al. Identification of epigenetically regulated genes that predict patient outcome in neuroblastoma. BMC Cancer 11, 66 (2011).

59. Martinez, R. et al. A microarray-based DNA methylation study of glioblastoma multiforme. Epigenetics 4, 255-264 (2009).
60. Tong, S. Y. et al. Frequent inactivation of hSRBC in ovarian cancers by promoter CpG island hypermethylation. Acta Obstet. Gynecol. Scand. 89, 629-635 (2010)

61. $\mathrm{Xu}, \mathrm{X}$. L. et al. Inactivation of human SRBC, located within the 11p15.5-p15.4 tumor suppressor region, in breast and lung cancers. Cancer Res. 61, 7943-7949 (2001).

62. Zochbauer-Muller, S. et al. Expression of the candidate tumor suppressor gene hSRBC is frequently lost in primary lung cancers with and without DNA methylation. Oncogene 24, 6249-6255 (2005).

63. Sasaki, K. et al. Identification of members of the protein phosphatase 1 gene family in the rat and enhanced expression of protein phosphatase 1 alpha gene in rat hepatocellular carcinomas. Jpn. J. Cancer Res.: Gann 81, 1272-1280 (1990).

64. Hsu, L. C., Huang, X., Seasholtz, S., Potter, D. M. \& Gollin, S. M. Gene amplification and overexpression of protein phosphatase lalpha in oral squamous cell carcinoma cell lines. Oncogene 25, 5517-5526 (2006).

65. Hanahan, D. \& Weinberg, R. A. The hallmarks of cancer. Cell 100, 57-70 (2000).

66. Huang, X. et al. Cytometric assessment of DNA damage in relation to cell cycle phase and apoptosis. Cell Prolif. 38, 223-243 (2005).

67. Hill, M. M. et al. PTRF-Cavin, a conserved cytoplasmic protein required for caveola formation and function. Cell 132, 113-124 (2008).

68. Kovtun, O. et al. Leishmania cell-free protein expression system. Methods $\mathbf{5 5}$, 58-64 (2011)

69. Thomas, N. B. et al. Growth of hormone-dependent MCF-7 breast cancer cells is promoted by constitutive caveolin-1 whose expression is lost in an EGF-Rmediated manner during development of tamoxifen resistance. Breast Cancer Res. Treat. 119, 575-591 (2010).

70. Wang, F., Gu, H. M. \& Zhang, D. W. Caveolin-1 and ATP binding cassette transporter A1 and G1-mediated cholesterol efflux. Cardiovasc Hematol. Disord. Drug Targets 14, 142-148 (2014).

71. Fiucci, G., Ravid, D., Reich, R. \& Liscovitch, M. Caveolin-1 inhibits anchorageindependent growth, anoikis and invasiveness in MCF-7 human breast cancer cells. Oncogene 21, 2365-2375 (2002).

72. Wu, P. et al. Growth suppression of MCF-7 cancer cell-derived xenografts in nude mice by caveolin-1. Biochem. Biophys. Res. Commun. 376, 215-220 (2008).

73. Johnston, W. A. \& Alexandrov, K. Production of eukaryotic cell-free lysate from Leishmania tarentolae. Methods Mol. Biol. 1118, 1-15 (2014).

74. Ruelcke, J. E., Loo, D. \& Hill, M. M. Reducing the cost of semi-automated ingel tryptic digestion and GeLC sample preparation for high-throughput proteomics. J. Proteom. 149, 3-6 (2016).

75. Inder, K. L. et al. Expression of PTRF in PC-3 Cells modulates cholesterol dynamics and the actin cytoskeleton impacting secretion pathways. Mol. Cell Proteom. 11, M111 012245 (2012).

\section{Acknowledgements}

We would like to thank Nicholas Ariotti for valuable discussion. Thanks to Sachini Fonseka and Ye-Wheen Lim for proofreading the article. This work was supported by fellowships and grants from the National Health and Medical Research Council of Australia (to R.G.P., grant numbers 569542 and 1045092) and to (R.G.P., A.S.Y., and K.A., grant number 1037320). M.M.H. was supported by a Fellowship from the Australian Research Council (FT120100251). Confocal microscopy was performed at the Australian Cancer Research Foundation (ACRF)/Institute for Molecular Bioscience (IMB) Dynamic Imaging Facility for Cancer Biology, established with funding from the ACRF. The authors acknowledge the facilities, and the scientific and technical assistance, of the Australian Microscopy \& Microanalysis Research Facility at the Centre for Microscopy and Microanalysis, The University of Queensland and the Proteomic Facility at UQ Diamantina Institute and Translational Research Institute. We acknowledge Alun Jones and the IMB Mass Spectromewtry Facility. The BirA/BioID constructs were kindly provided by the Burke Laboratory, Singapore and the PP1alpha construct was kindly provided by Laura Trinkle-Mulcahy, Canada.

\section{Author contributions}

K.A.M., Y.W., and R.G.P. conceived the study. K.A.M. performed the biotin/mass spectrometry experiments, interpreted the data, and wrote the paper with R.G.P., A.Y., and K.A. Y.W. performed all PP1/Cavin $1-3 / \gamma-\mathrm{H} 2 \mathrm{AX}$ experiments and wrote that section of the paper, Y.G. and E.S. performed single-molecule analysis and the ALPHAScreen, V. T. made the PP1 phosphorylation constructs, S.O. made the BirA-Cavin1 and Cavin3 constructs, T.H. and N.M. made the PP1 $\alpha$ cell-free-expression vector, J.R. and M.M.H. performed mass spectrometry analysis, C.F. performed Electron Microscopy, and S.V.M performed the AlphaLISA analysis. All authors provided useful insights and commented on the paper. 


\section{Additional information}

Supplementary Information accompanies this paper at https://doi.org/10.1038/s41467019-11111-1.

Competing interests: The authors declare no competing interests.

Reprints and permission information is available online at http://npg.nature.com/ reprintsandpermissions/

Peer review information: Nature Communications would like to thank Peter Michaely, Ivan Nabi, Stephen Tait and the anonymous reviewers for their contributions to the peer review of this work. Peer review reports are available.

Publisher's note: Springer Nature remains neutral with regard to jurisdictional claims in published maps and institutional affiliations. (c) (i) Open Access This article is licensed under a Creative Commons Attribution 4.0 International License, which permits use, sharing, adaptation, distribution and reproduction in any medium or format, as long as you give appropriate credit to the original author(s) and the source, provide a link to the Creative Commons license, and indicate if changes were made. The images or other third party material in this article are included in the article's Creative Commons license, unless indicated otherwise in a credit line to the material. If material is not included in the article's Creative Commons license and your intended use is not permitted by statutory regulation or exceeds the permitted use, you will need to obtain permission directly from the copyright holder. To view a copy of this license, visit http://creativecommons.org/ licenses/by/4.0/.

(C) The Author(s) 2019 